\title{
过渡金属催化环加成反应合成八元碳环研究进展(2010～2020)
}

\author{
王路宁＼cjkstart余志祥* \\ (北京大学化学与分子工程学院 北京分子科学国家研究中心 \\ 生物有机与分子工程教育部重点实验室 北京 100871)
}

\begin{abstract}
摘要 八元碳环结构广泛存在于天然产物、药物分子(如紫杉醇和瑞他帕林)和香料分子等功能分子中. 许多含有八元碳 环的天然产物如 vinigrol 和 ophiobolin(蛇狍假壳素)都显示出较好的生物活性. 因此, 合成这些含有八元碳环的分子将 会为药物化学、化学生物学、香料化学、材料化学和其它科学的发展提供分子基础. 八元碳环的合成一直是有机合成 化学中的挑战之一. 为了迎接这一挑战, 许多卓有成就的化学家发展出了许多金属催化的环加成反应以合成八元碳环, 从而为高效、原子经济性和步骤经济性地合成目标分子提供帮助. 在 2010 年时, 我们曾经对利用过渡金属催化的环加 成反应制备八元碳环这一前沿方向进行过总结. 本综述总结了 2010 2020 年期间该领域的最新进展，内容包括新型环 加成反应的发展、环加成反应的应用以及机理研究, 希望可以为关注此领域的有机化学家提供一定的启发和有益的指 引，同时鼓励更多合成化学家利用这些环加成反应进行各种功能分子的合成，并发展出更多用于八元碳环合成的高效 方法.
\end{abstract}

关键词 八元碳环; 过渡金属催化; 环加成; 全合成

\section{Transition-Metal-Catalyzed Cycloadditions for the Synthesis of Eight-Membered Carbocycles: An Update from 2010 to 2020}

\author{
Wang, Lu-Ning Yu, Zhi-Xiang* \\ (Beijing National Laboratory for Molecular Sciences, Key Laboratory of Bioorganic Chemistry and Molecular Engineering of \\ Ministry of Education, College of Chemistry and Molecular Engineering, Peking University, Beijing 100871)
}

\begin{abstract}
Eight-membered carbocycles are widely found in natural products with significant biological activities and other molecules ranging from perfumes to potential materials. Therefore, accessing these eight-membered carbocycle embedded molecules is important for drug discovery, biological investigation, fragrance industry, material development and many other fields. However, the synthesis of eight-membered carbocycles is still posing challenges to synthetic chemists. Hence, tremendous efforts have been endeavored by many leading chemists to discover and develop new reactions in order to synthesize eight-membered carbocycles. Among these reactions, transition-metal-catalyzed cycloadditions of $[m+n],[m+n+o],[m+$ $n+o+p]$ have evolved as powerful tools to achieve this aim. This topic has been reviewed in 2010. Summarized here are many new developments in this field and applications of the previously developed reactions in natural product synthesis since then.

Keywords eight-membered carbocycles; transition metal catalysis; cycloaddition; total synthesis
\end{abstract}

Molecules containing eight-membered carbocycles exist widely in natural products. ${ }^{[1]}$ Many of these natural products have significant biological activities and some of them have been developed as useful drugs, such as anticancer drug taxol $^{[2]}$ (from yew) and antibacterial drug retapamulin ${ }^{[3]}$ (a derivative from pleuromutilin). Thus, obtaining these natural products and their analogs for further investigation in medicinal chemistry, chemical biology and other related areas has become paramount. Considering that isolation of these molecules from natural resources usually affords very limited amounts of compounds, which prevents both direct extensive biological studies of these natural products and further derivatization of these molecules to obtain their analogs, chemical synthesis in most cases is the only way to achieve this goal. In addition, chemical synthesis can in principle provide "flexible" derivatized products compared

\footnotetext{
* Corresponding author. E-mail: yuzx@ pku.edu.cn.

Received October 16, 2020; revised November 9, 2020; published online November 11, 2020.

Dedicated to the 40th anniversary of Chinese Journal of Organic Chemistry and 70th anniversary of the Shanghai Institute of Organic Chemistry, Chinese Academy of Sciences.
} 
to the "rigid" analogs that are directly transformed from natural products (Scheme 1, A). Furthermore, eight-membered carbocycles are found in fragrant molecules ${ }^{[4]}$ and potential material molecules, ${ }^{[5]}$ suggesting that the synthesis of these molecules are also important and valuable for our society (Scheme 1, B). Unfortunately, the synthesis of eight-membered carbocycles still poses significant challenges to synthetic chemists, which dramatically impedes further downstream investigations in various research fields that heavily rely on the use of these molecules.

Highly efficient synthesis of ring compounds depends on both quantity (the number of reactions) and quality (the efficiency and scope of a reaction) of the cycloadditions in a chemist's arsenal, and the synthetic strategies/tactics, which are referred here to ways of applying non-cycloaddition reactions for ring formation. If there are many cycloaddition reactions with broad scope and high efficiency for building desired rings directly, chemists could then have many options to synthesize their target rings. For example, sixmembered carbocycles can be achieved by many cycloaddition reactions such as Diels-Alder reaction, ${ }^{[6]}$ metal- catalyzed cycloadditions such as $[4+2],{ }^{[7]}[5+1],{ }^{[8]}[3+2+$ $1]^{[9]}$ and $[2+2+2]^{[10]}$ reactions to name a few. The synthetic strategies for ring formation include ring-closure, which uses reactions (such as intramolecular $S_{\mathrm{N}} 2$ reactions, addition reactions, coupling reactions and $\mathrm{RCM}^{[11]}$ etc.), to make two functional groups at the two ends of a linear molecule to react and close the ring simultaneously, ring expansion/contraction and others. For synthesis of five- and six-membered carbocycles, there is a choice of many cycloaddition reactions and strategies. But for synthesis of eight-membered carbocycles, both the number of cycloadditions and the strategies are limited. This is reflected in a recent review from $\mathrm{Li}$ and coworkers. ${ }^{[12]}$ In their review paper, many elegant total syntheses of natural products with eight-membered carbocycles in the past ten years have been highlighted. But among them, only one metal-catalyzedcycloaddition for eight-membered carbocycle synthesis, the Rh-catalyzed $[5+2+1]$ cycloaddition, was applied for the total synthesis. ${ }^{[13]}$ The synthesis of other natural products in Li's review paper is mainly based on ring-closure strategy. Unfortunately, the ring-closure strategy is usually limited to molecules having appropriate conformations that can overcome enthalpy and entropy penalties associated with the synthesis of seven-, eight- and nine-membered rings. ${ }^{[14]}$ Therefore, ring-closure strategy is not general for achieving synthesis of eight-membered carbocycles. Furthermore, strategies other than ring-closure for eight-membered rings are very limited (for example, ring expansion for eight-membered carbocycles are not easy because seven-membered carbocycles are also difficult to access). In addition, the traditional pericyclic cycloadditions to eightmembered rings such as [4+4], [6+2] reactions under thermal reaction conditions are forbidden based on Woodward-Hoffman rules and frontier molecular orbital (FMO) theories, further increasing hurdles for the synthesis of eight-membered carbocycles compared to the syn- thesis of six-membered rings.

Therefore, the most powerful and direct approach to overcome the challenges of synthesizing eight-membered carbocycles is to develop new cycloaddition reactions. Transition-metal-catalyzed cycloadditions have evolved as powerful reactions to directly synthesize eight-membered carbocycles $^{[1 \mathrm{~b}-1 \mathrm{c}, 15]}$ (Scheme 1, C). In 2010, we had reviewed this and summarized many outstanding progresses in this area. ${ }^{[16]}$ Ten years have passed since then. Here we want to update the progresses in this field aiming to highlight the development of new metal-catalyzed cycloadditions for eight-membered carbocycle synthesis, the applications on natural product synthesis using these cycloaddition reactions, together with some mechanistic studies of these reactions as well (Scheme 1, D). We want to point out here is that, the cycloaddition reactions catalyzed by transition metals acting as Lewis acids do not belong to the transition-metal-catalyzed cycloadditions and progresses in this direction are not included.

\section{1 [4+4] cycloadditions}

Since the first metal-catalyzed $[4+4]$ cycloaddition of bisdienes was discovered by Ziegler and Reed ${ }^{[17]}$ various inter- and intramolecular $[4+4]$ cycloadditions have been developed by using different catalysts. In 1986, Wender and coworkers $^{[18]}$ reported a nickel-catalyzed intramolecular $[4+4]$ cycloaddition of bisdienes to give cis-5/8 and trans-6/8 bicyclic products (Scheme 2, A). In 2016, Chung and coworkers ${ }^{[19]}$ reported a rhodium-catalyzed intramolecular [4+4] cycloaddition of bisdienes (Scheme 2, B). Different from Wender's $[4+4]$ reaction, the Rh-catalyzed cycloaddition gave cis-5/8 and cis-6/8 bicycles, as demonstrated by the reactions of $\mathbf{2 - 1}$ and $\mathbf{2 - 3}$ to the [4+4] cycloadducts 2-2 and 2-4 respectively. It is interesting to find that substrate 2-5 with a phenyl substituent at the distal position of dienes gave $[4+2]$ product $\mathbf{2 - 6}$, not $[4+4]$ product. Density functional theory (DFT) studies further confirmed that the selectivity of $[4+4]$ and $[4+2]$ cycloadditions for bisdienes is determined by the trans or cis configuration of butadienyl group in the reaction intermediates.

In 2018, Frontera, Vidal-Ferran and coworkers ${ }^{[20]}$ carried out a detailed investigation of Wender's nickel-catalyzed $[4+4]$ cycloaddition of bisdienes through experiments and DFT calculations (Scheme 2, C). They tested several phosphine ligands with different electronic effects, finding that electron-rich triarylphosphines were efficient ligands for the cycloadditions. The authors also investigated the stereoselectivity of the $[4+4]$ cycloaddition. DFT calculations and experiments confirmed that the tether length between two diene moieties and the geometries of alkenes in the substrates influenced the configuration of products. If two dienes were linked by three atoms, the cycloadducts were $c i s-5 / 8$ bicycles. When two dienes were linked by four atoms, the cycloadducts were either cis- or trans-6/8 bicycles, depending on the geometries of the diene moiety 

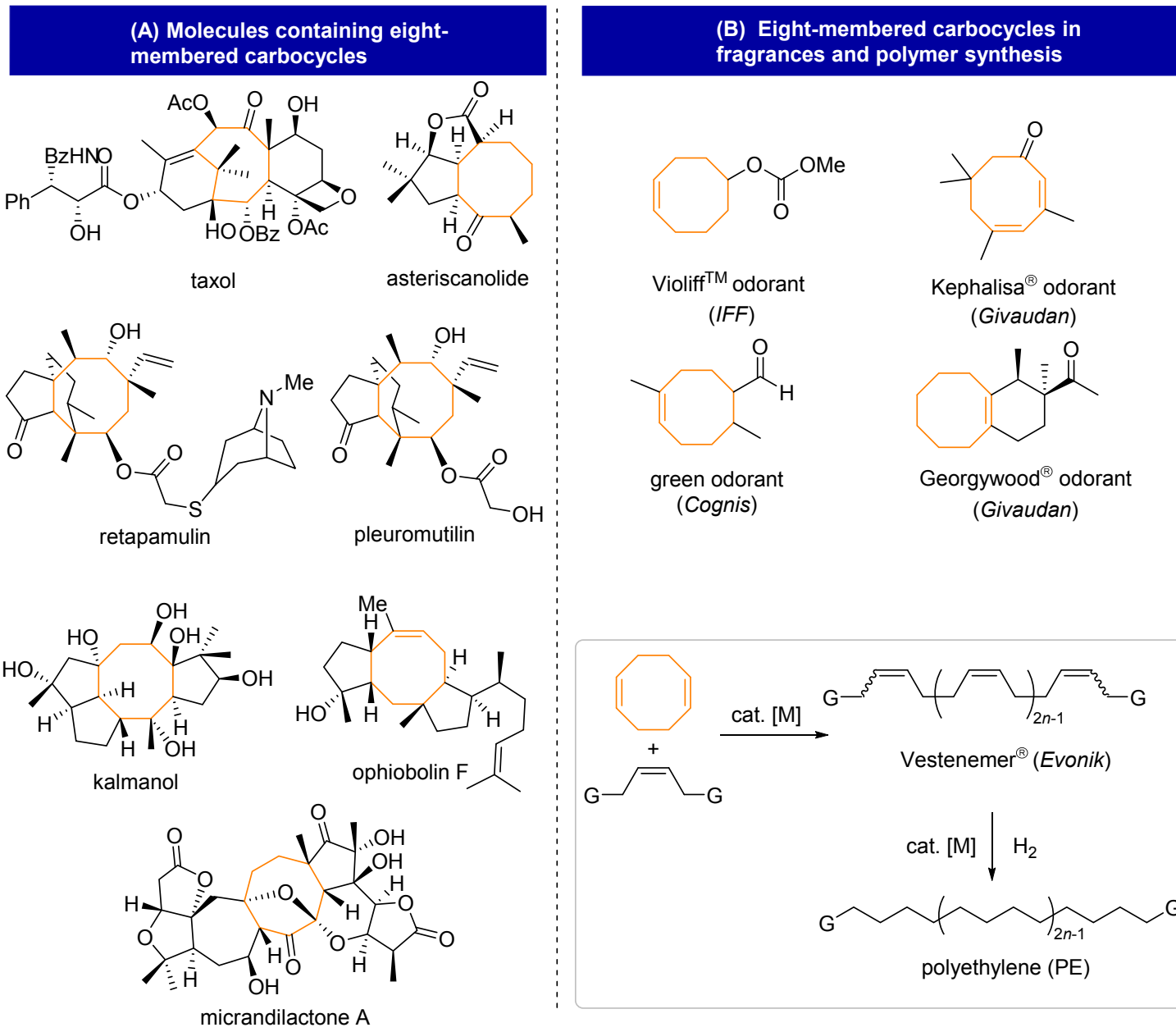

fragrances and polymer synthesis

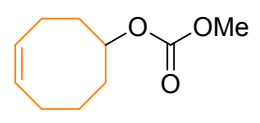

Violiff ${ }^{\mathrm{TM}}$ odorant (IFF)

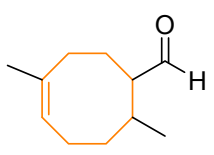

green odorant

(Cognis)

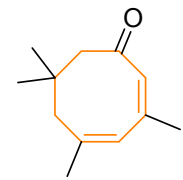

Kephalisa ${ }^{\circledR}$ odoran (Givaudan)

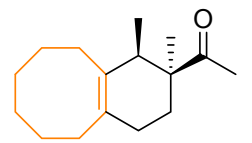

Georgywood $^{\circledR}$ odorant (Givaudan)

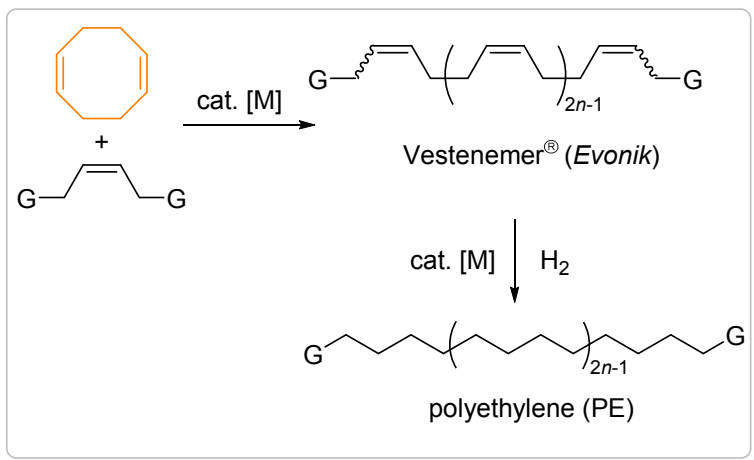

\section{(C) Transition-metal-catalyzed $[m+n+o]$ cycloaddition}

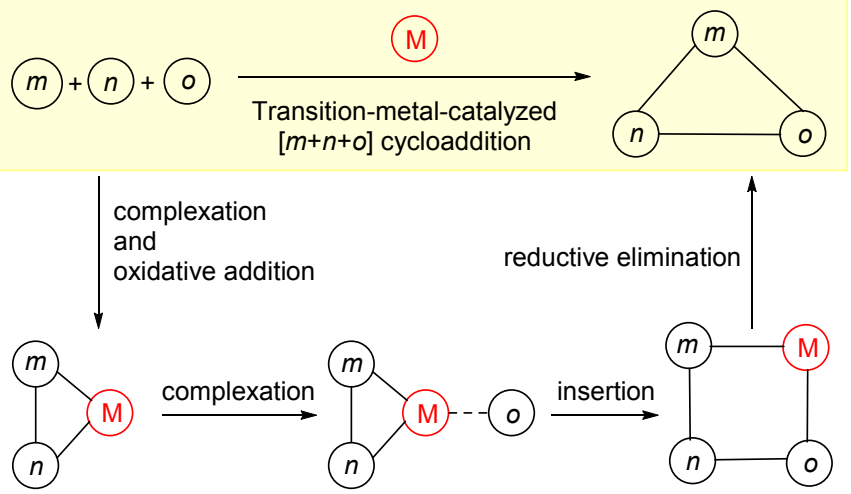

(D) Transition-metal-catalyzed cycloadditions to eight-memberedcarbocycles

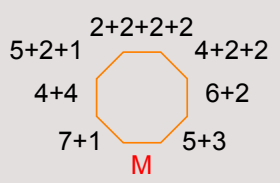

$\mathrm{Ti}, \mathrm{Cr}, \mathrm{Fe}, \mathrm{Co}, \mathrm{Ni}, \mathrm{Mo}$

$\mathrm{Ru}, \mathrm{Rh}, \mathrm{Pd}, \mathrm{Pt}, \mathrm{Au} \cdots$

Scheme 1 (A) Molecules containing eight-membered carbocycles, (B) eight-membered carbocycles in fragrances and polymer synthesis. (C) transition-metal-catalyzed $[m+n+o]$ cycloaddition and (D) transition-metal-catalyzed cycloadditions to eight-membered carbocycles

in the substrates. The $E / Z$-configured substrate, for example E,Z-2-3, generated $c i s-6 / 8$ cycloadduct $c i s-2-4$, whereas the $E, E$-configured substrate, for example, $E, E-\mathbf{2}-\mathbf{3}$, generated trans-6/8 product trans-2-4.

Intermolecular cyclodimerization or cross- $[4+4]$ cycloaddition of two 1,3-dienes provides a valuable method to construct eight-membered monocyclic carbocycles. In the early 1950s, chemists discovered that nickel complexes can catalyze the dimerization of butadienes. ${ }^{[17]}$ In the 1980 s, iron complexes were applied to this reaction and an asymmetric version was realized when a chiral ligand was used. ${ }^{[21]}$ But for a long time, the structure and oxidation state of the active iron catalysts in such reactions have remained unknown, partly because various kinds of additional activating reagents were needed to activate the precatalysts. The lack of exact structure of real active species in reaction 
(A) Nickel catalyzed intramolecular [4+4] cycloaddition of bisdienes (Wender)
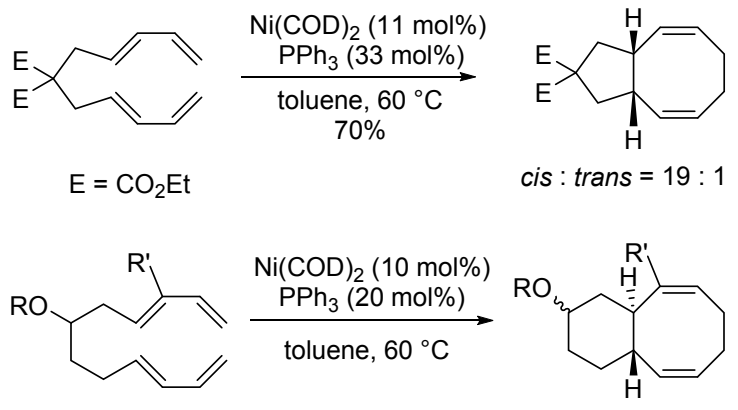

trans-6/8 product

$\mathrm{R}=\mathrm{Ac}, \mathrm{R}^{\prime}=\mathrm{Me}, 82 \%$

$\mathrm{R}=\mathrm{TBDMS}, \mathrm{R}^{\prime}=\mathrm{H}, 92 \%$

\section{(B) Rhodium catalyzed intramolecular [4+4]} cycloaddition of bisdienes (Chung)

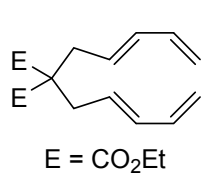

2-1

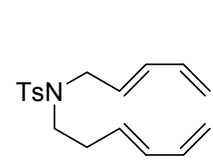

2-3

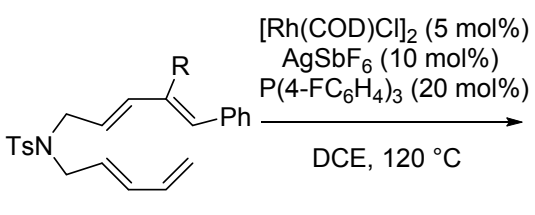

2-5

$$
\begin{gathered}
\underset{\begin{array}{c}
{\left[\mathrm{Rh}(\mathrm{COD}) \mathrm{Cl}_{2}(5 \mathrm{~mol} \%)\right.} \\
\mathrm{AgSbF}_{6}(10 \mathrm{~mol} \%)
\end{array}}{\longrightarrow} \\
\underset{78 \%}{\mathrm{DCE}, 100{ }^{\circ} \mathrm{C}}
\end{gathered}
$$

$\left[\mathrm{Rh}(\mathrm{COD}) \mathrm{Cl}_{2}(5 \mathrm{~mol} \%)\right.$ $\mathrm{AgSbF}_{6}\left(10 \mathrm{~mol}^{\circ}\right)$

$60{ }^{\circ} \mathrm{C}, 58 \%$
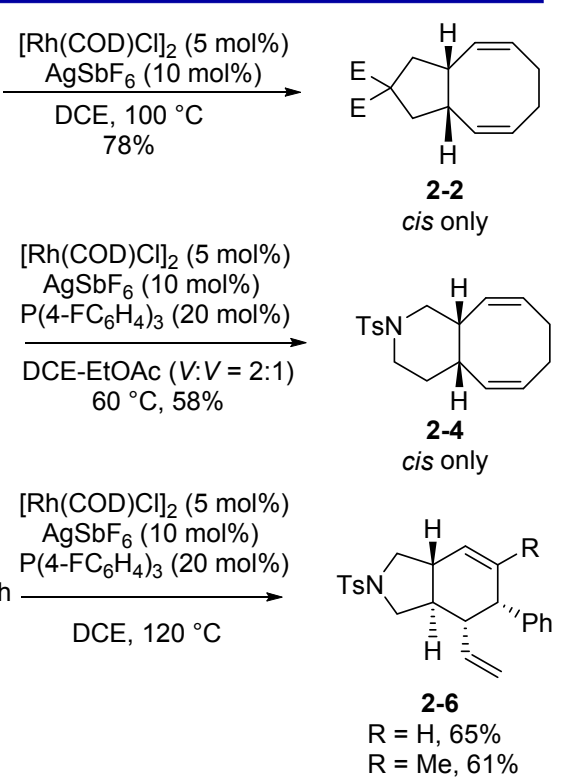

(C) Conditions optimization and stereoselectivity study of nickel catalyzed intramolecular $[4+4]$ cycloaddition of bisdienes (Frontera and Vidal-Ferran)

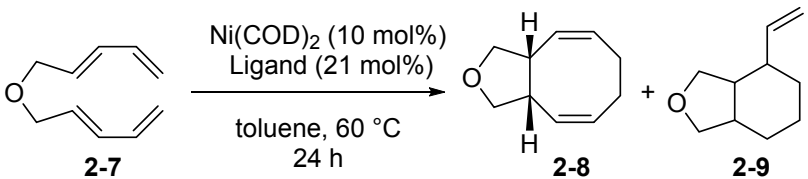

$$
\mathrm{Ph}_{3} \mathrm{P} \quad\left(4-\mathrm{MeO}-\mathrm{C}_{6} \mathrm{H}_{4}\right)_{3} \mathrm{P} \quad\left(4-\mathrm{CF}_{3}-\mathrm{C}_{6} \mathrm{H}_{4}\right)_{3} \mathrm{P}
$$

2-L1

2-L2

2-L3
$\left(2-\mathrm{Me}-\mathrm{C}_{6} \mathrm{H}_{4} \mathrm{O}\right)_{3} \mathrm{P}$

2-L4

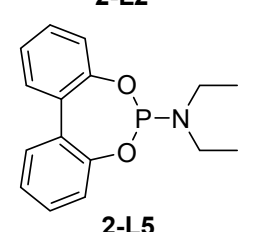

2-L5

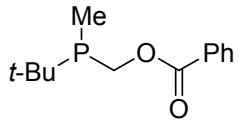

2-L6

\begin{tabular}{lcccccc}
\hline Ligand & 2-L1 & 2-L2 & 2-L3 & 2-L4 & 2-L5 & 2-L6 \\
\hline Conv./\% & 99 & 98 & 97 & 74 & 99 & 38 \\
Yield/\% of 2-8 & $58(52)$ & $57(56)$ & 28 & 42 & $56(46)$ & 10 \\
Yield/\% of 2-9 & 6 & $<1$ & 8 & - & $22(16)$ & - \\
\hline
\end{tabular}<smiles>C=C/C=C\CCN([AlH2])C/C=C/C=C</smiles>

$E, Z-2-3$<smiles>C=C/C=C\CCN([Te])C/C=C/C=C</smiles>

$E, E-2-3$

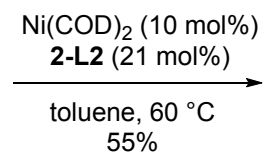

$55 \%$

$\mathrm{Ni}(\mathrm{COD})_{2}(10 \mathrm{~mol} \%)$ 2-L2 $(21 \mathrm{~mol} \%)$

toluene, $60{ }^{\circ} \mathrm{C}$ $78 \%$

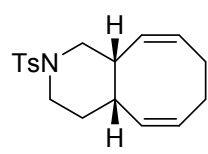

cis-2-4

trans-2-4

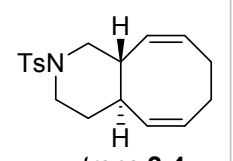

Scheme 2 (A) Nickel-catalyzed intramolecular [4+4] cycloaddition of bisdienes by Wender; (B) rhodium-catalyzed intramolecular $[4+4]$ cycloaddition of bisdienes by Chung and (C) optimization of nickel-catalyzed [4+4] reaction and study of stereochemistry by Frontera and Vidal-Ferran

prevented chemists from developing more efficient catalysts which usually rely on the intensive studies of structure-activity relationship between catalysts and reaction efficiencies. In 2016, Ritter and coworkers ${ }^{[22]}$ prepared a new iron complex 3-2 and its structure was determined (Scheme 3, A).

Using 3-2 as catalyst, dimerization of butadiene to 1,5-cyclooctadiene could be achieved in 12000 TON (turnover number) without any additional activating reagent (Scheme 3, B). They found that 3-2 had a high-spin $(S=3 / 2)$ Fe center, coupled antiferromagnetically to a ligand-based diimine radical. The authors proposed that Fe-COD ligand antibonding orbital was critical for facile ligand exchange process in the catalytic cycle. A plausible mechanism for this reaction is given in Scheme 3, C.

In 2019, Chirik and coworkers ${ }^{[23]}$ reported a family of iron complexes bearing bidentate ligands, finding that these iron complexes can catalyze the $[4+4]$ cycloaddition of substituted 1,3-dienes to afford disubstituted 1,5-cycloocadienes, with good control of both chemo- and regio-selectivities (Scheme 4, A). The structures of the precatalysts were determined and the active species were characterized by in situ spectroscopic measurements. Their results showed that an (imino)pyridine ligand radical anion is antiferromagnetically coupled with a high-spin iron(I) center and this is the active catalyst in the reaction.

In 2020, an enantioselective chiral diamine-iron complex catalyzed cross-[4+4] cycloaddition of 1,3-dienes with alkyl substituents to afford chiral functionalized cyclooctadienes (CODs) was reported by Crammer and coworkers (Scheme 4, B). ${ }^{[24 a]}$ More than 18 cycloadducts were obtained in good yields and high enantioselectivities, 
Iron complex catalyzed cyclodimerization of butadiene (Ritter)

(A) Preparation of Iron complex

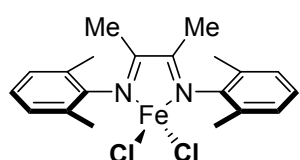

$\mathrm{MeMgCl}$ (3 equiv.)

butadiene/COD

$(V: V=3: 1,0.01 \mathrm{~mol} / \mathrm{L})$

Cl

$-50 \sim 23^{\circ} \mathrm{C}$

3-1

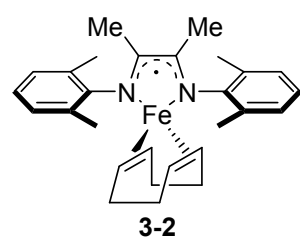

(B) Cyclodimerization of Butadienes

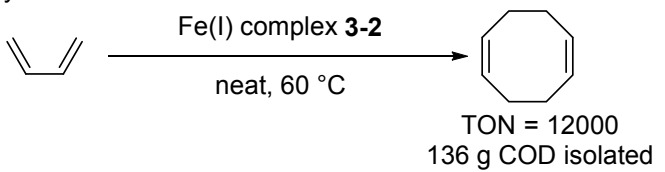

(C) Plausible mechanism

$85 \%$ yield after distillation

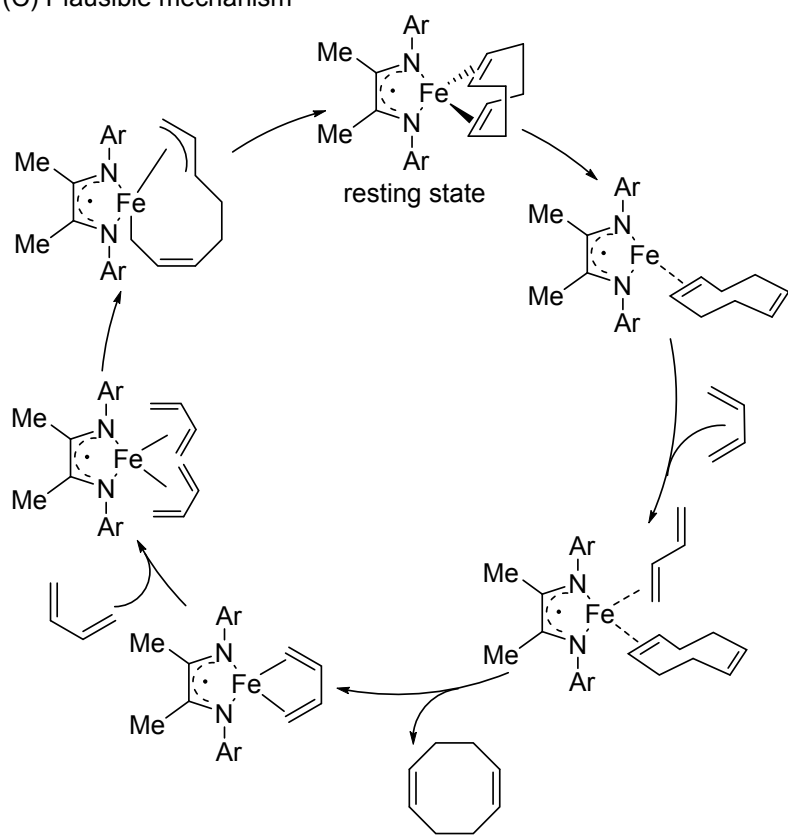

Scheme 3 Iron complex catalyzed cyclodimerization of butadiene by Ritter

(A) Preparation of iron complex, (B) Cyclodimerization of butadiene, (C) Plausible mechanism

which were contradictory to tom Dieck' single example of asymmetric $[4+4]$ reaction with a moderate enantio-selectivity, also catalyzed by chiral diamine-iron complex. ${ }^{[24 \mathrm{~b}]}$ The key to the success of Crammer's asymmetric [4+4] reaction was attributed to the tailored bulky side arms in the chiral diamine-iron catalyst, which can reach a balanced performance of reactivity, chemo- and stereo-selectivities for the $[4+4]$ reaction.

Metal-catalyzed $\mathrm{C}-\mathrm{C}$ bond activation of strained threeand four-membered rings have been widely applied to develop transition-metal-catalyzed cycloadditions. ${ }^{[25]}$ Among these strained small rings, benzocyclobutenones (BCBs) have been well developed in these years. ${ }^{[26]}$ In 2015 , Martin
(A) Iron complex catalyzed catalyst-controlled

cyclodimerization and cross [4+4] cycloaddition of substituted 1,3-dienes (Chirik)

(a) Cyclodimerization
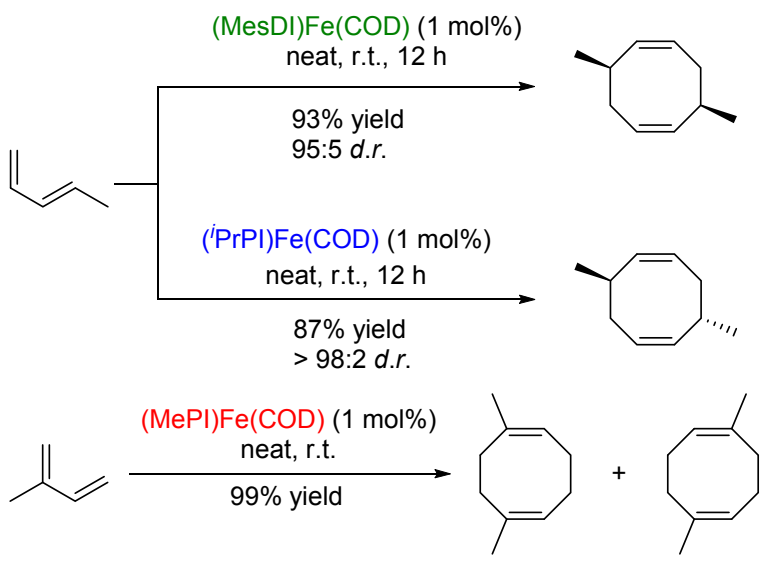

$(90: 10)$

(b) Cross-[4+4] cycloaddition
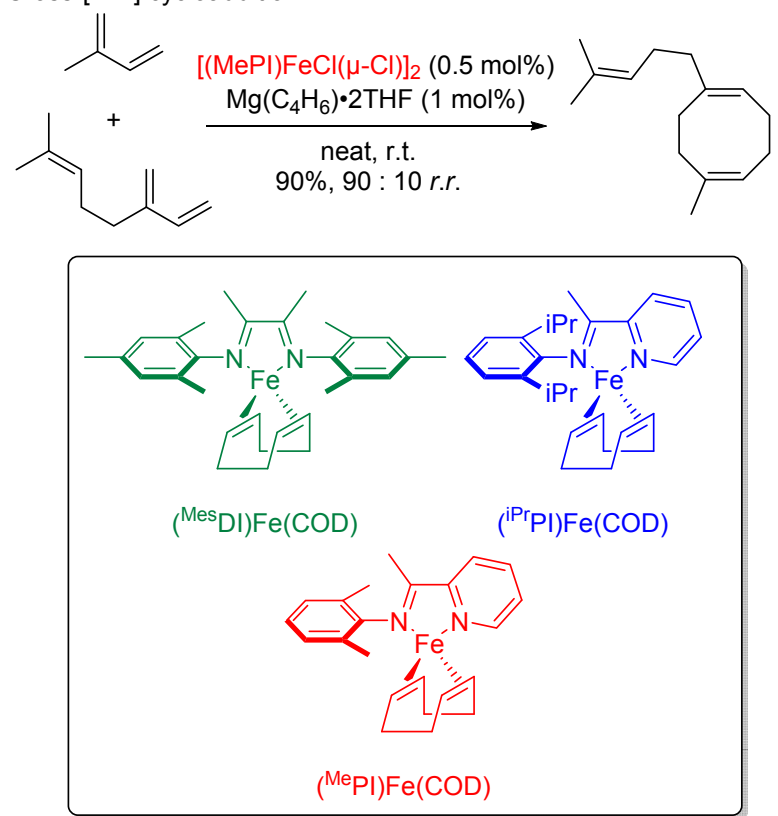

(B) Chiral DI-FeCl 2 catalyzed enantioselective cross-[4+4] cycloaddition of 1,3-dienes (Crammer)

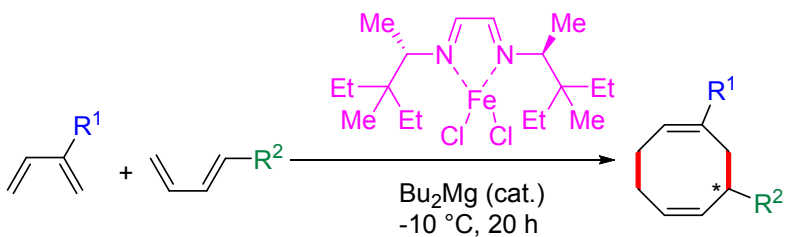

up to $99 \%$ yield, up to $97: 3$ er

Scheme 4 (A) Iron complex catalyzed catalyst-controlled cyclodimerization and cross-[4+4] cycloaddition of substituted 1,3-dienes by Chirik and (B) chiral DI- $\mathrm{FeCl}_{2}$ catalyzed enantioselective cross- $[4+4]$ cycloaddition of 1,3-dienes by Crammer and coworkers ${ }^{[27]}$ reported a nickel-catalyzed [4+4] cycloaddition of BCBs with 1,3-dienes to synthesize benzo- 
cyclooctadienones (Scheme 5). They optimized the reaction conditions by using BCB 5-1 and diene 5-2 as the substrates, $\mathrm{Ni}(\mathrm{COD})_{2}$ as the precatalyst, establishing that the electron-poor phosphine ligand, $\left(p-\mathrm{CF}_{3}-\mathrm{C}_{6} \mathrm{H}_{4}\right)_{3} \mathrm{P}$, was the best ligand for the reaction and the final product 5-3 was obtained in $98 \%$ yield under the optimal reaction conditions. More than a dozen of substrates were found suitable for the $[4+4]$ cycloaddition. A plausible mechanism was proposed by the authors: an oxidative cyclometallation of carbonyl group of 5-4, diene 5-5 and nickel catalyst occurs to generate five-membered nickelacycle $\mathbf{5 - A}$, followed by a $\beta$-carbon elimination to give seven-membered metallacycle, which might lead to the formation of putative $\pi$-allyl Ni(II) metallacycle 5-B. Then intermediate 5-B undergoes reductive elimination to give the final benzocyclooctadienone product 5-6. But DFT calculations by Li et al. ${ }^{[28]}$ and Huang

Nickel catalyzed [4+4] cycloaddition of benzocyclobutenone (BCBs) with 1,3-dienes

(A) Experiments of Ni Catalyzed [4+4] Cycloaddition of BCBs with 1,3-dienes

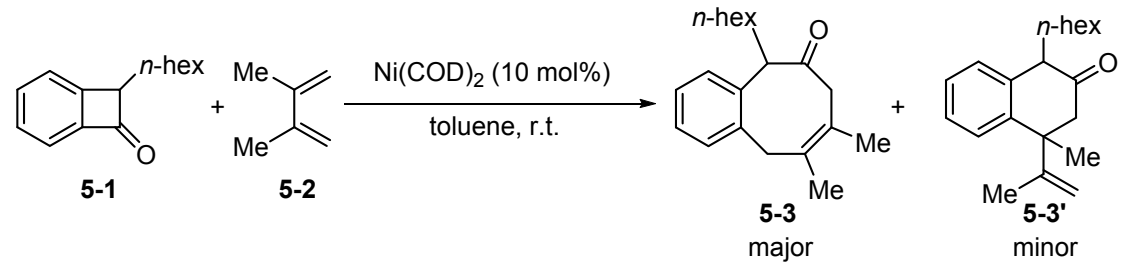

\begin{tabular}{|c|c|c|c|c|c|}
\hline Ligand & $\mathrm{Ph}_{3} \mathrm{P}$ & $\left(p-\mathrm{MeO}-\mathrm{C}_{6} \mathrm{H}_{4}\right)_{3} \mathrm{P}$ & $\left(p-\mathrm{CF}_{3}-\mathrm{C}_{6} \mathrm{H}_{4}\right)_{3} \mathrm{P}$ & $\mathrm{Cy}_{3} \mathrm{P}$ & $\mathrm{Ph}_{2} \mathrm{P} \frown \mathrm{PPh}_{2}$ \\
\hline Yield of 5-3 & $71 \%$ & $62 \%$ & $98 \%$ & $5 \%$ & 0 \\
\hline
\end{tabular}

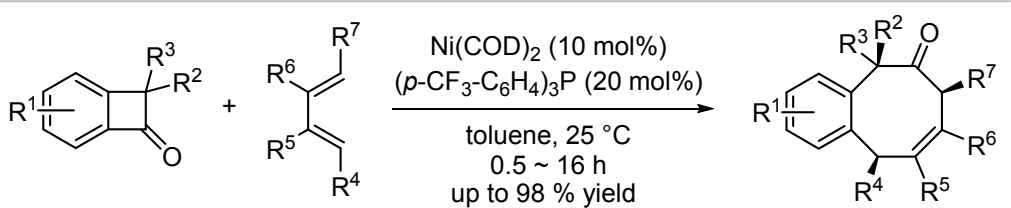

(B) Mechanism Proposed by Martin et al.

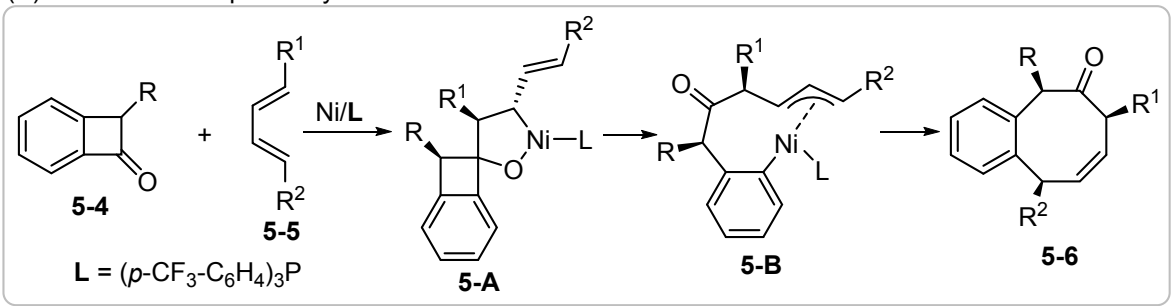

(C) DFT Supported Mechanism Proposed by Li et al. and Huang et al.

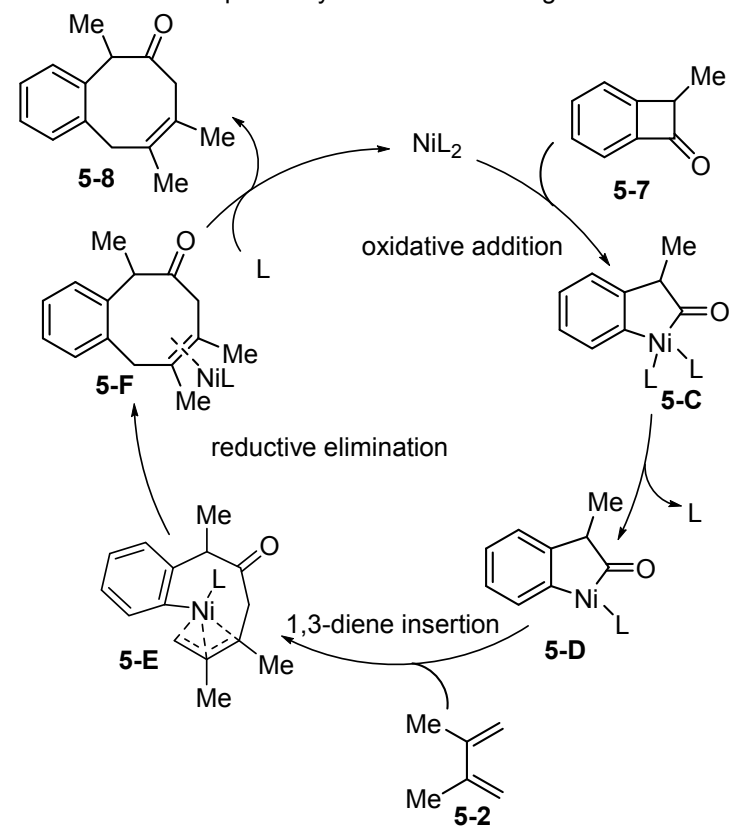

Scheme 5 Nickel-catalyzed [4+4] cycloaddition of benzocyclobutenones with 1,3-dienes 
et al. ${ }^{[29]}$ did not support the originally proposed mechanism and a revised mechanism was proposed, which includes these steps: a direct oxidative addition of $\mathrm{BCB}$ 5-7 with nickel catalyst generates five-membered nickelacycle 5-C, then a concerted 1,3-diene insertion into $\mathrm{Ni}-\mathrm{C}$ bond of 5-D takes place. Finally, reductive elimination of 5-E affords the [4+4] cycloadduct 5-8.

\section{$2[2+2+2+2]$ cycloadditions}

The first $[2+2+2+2]$ cycloaddition of acetylene to form cyclooctatetraene (COT) was achieved by using nickel complex as the catalyst. ${ }^{[30]}$ Since then, a variety of $[2+2+$ $2+2$ ] cycloadditions of alkynes were developed. In 2007, a $[2+2+2+2]$ cycloaddition of two diynes affording a tricyclic product with a COT ring was developed by Wender and coworkers. ${ }^{[31]}$ Besides, Zhao and coworkers ${ }^{[32]}$ found that two 1,6-enynes could undergo $[2+2+2+2]$ cycloaddition to give 1,5-cyclooctadienes (CODs). In all these cycloadditions to form either COTs or CODs, nickel catalysts were necessary.

In 2014, Croatt and coworkers accidentally developed the first rhodium-catalyzed $[2+2+2+2]$ cycloaddition of two diynes (Scheme 6) ${ }^{[33]}$ Originally they planned to synthesize oxazines from diynes and nitrosobenzene by using $\left[\mathrm{Rh}(\mathrm{CO})_{2} \mathrm{Cl}\right]_{2}$ as the catalyst. To their surprise, no desired product was obtained for substrate 6-1. Instead, substituted benzenes from $[2+2+2]$ cycloaddition as the major products together with a small amount of COT from $[2+$ $2+2+2$ ] cycloaddition as the minor product were generated. No COT was generated when nitrosobenzene was removed from the reaction system. After screening different polar compounds as the possible additives to improve the reaction yield, they found that dimethyl sulfoxide (DMSO) gave the best results. The optimal conditions for diyne substrates, are carrying out the $[4+4]$ reaction in tetrahydrofuran (THF) or $\mathrm{CDCl}_{3}$ at $55{ }^{\circ} \mathrm{C}$ for $2 \mathrm{~d}$, using $10 \mathrm{~mol} \%$ $\left[\mathrm{Rh}(\mathrm{CO})_{2} \mathrm{Cl}\right]_{2}$ as the catalyst and $10 \mathrm{~mol} \% \mathrm{DMSO}$ as the additive. All the $[4+4]$ reactions proceeded with $75 \%$ conversion and the ratio of COTs $([2+2+2+2]$ cycloadducts) to substituted benzenes $([2+2+2]$ cycloadducts $)$ in final products was up to $1.4 \sim 1.5: 1$. The authors investigated the reaction mechanism by using ReactIR, proposing that DMSO might coordinate with the rhodium species and favor the third alkyne insert into the $\mathrm{Rh}-\mathrm{C}$ bond in 6-B. Otherwise, 6-B could directly undergo reductive elimination to give $[2+2+2]$ product. The authors also explained why adding DMSO slowed the reaction, hypothesizing that DMSO might increase the barrier for reductive elimination of rhodacycloheptatriene 6-B.

\section{3 [4+2+2] cycloadditions}

The first $[4+2+2]$ cycloaddition to construct eightmembered carbocycles was discovered in 1970 by Carbonaro and coworkers, ${ }^{[34]}$ using norbornadienes (NBDs) and dienes as the substrates and iron complex as the catalyst. Since then, various types of metal-catalyzed $[4+2+2]$
Rhodium-catalyzed intramolecular $[2+2+2+2]$ cycloaddition of diynes (Croatt)

(A) Discovery of Rh-catalyzed [2+2+2+2] cycloaddition of diynes
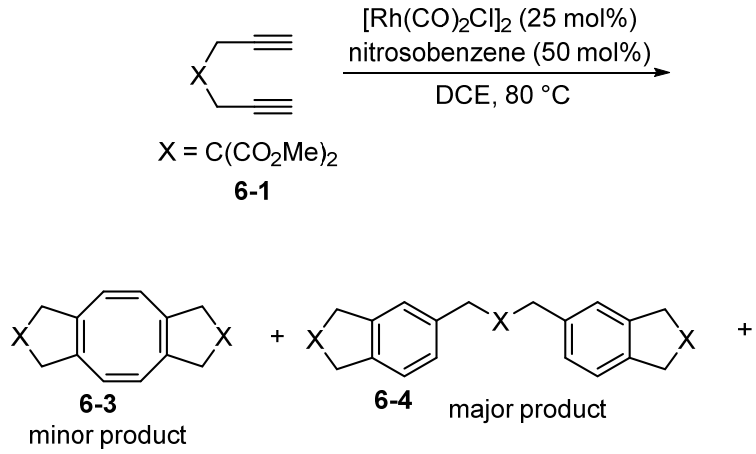

minor product
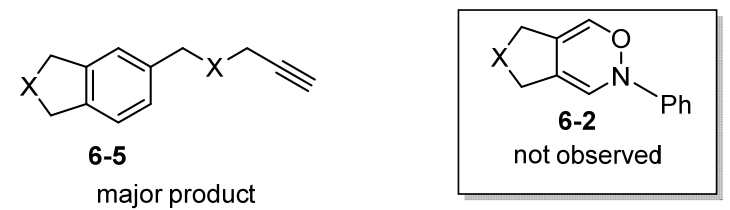

(B) Reaction optimization

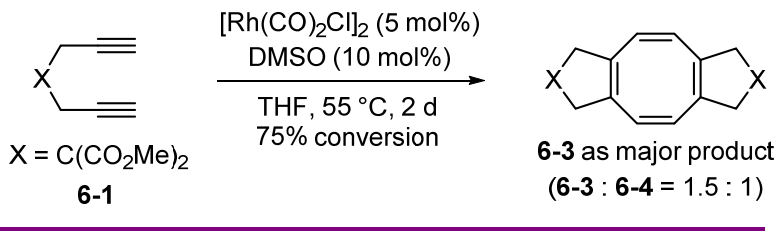

(C) Proposed mechanism

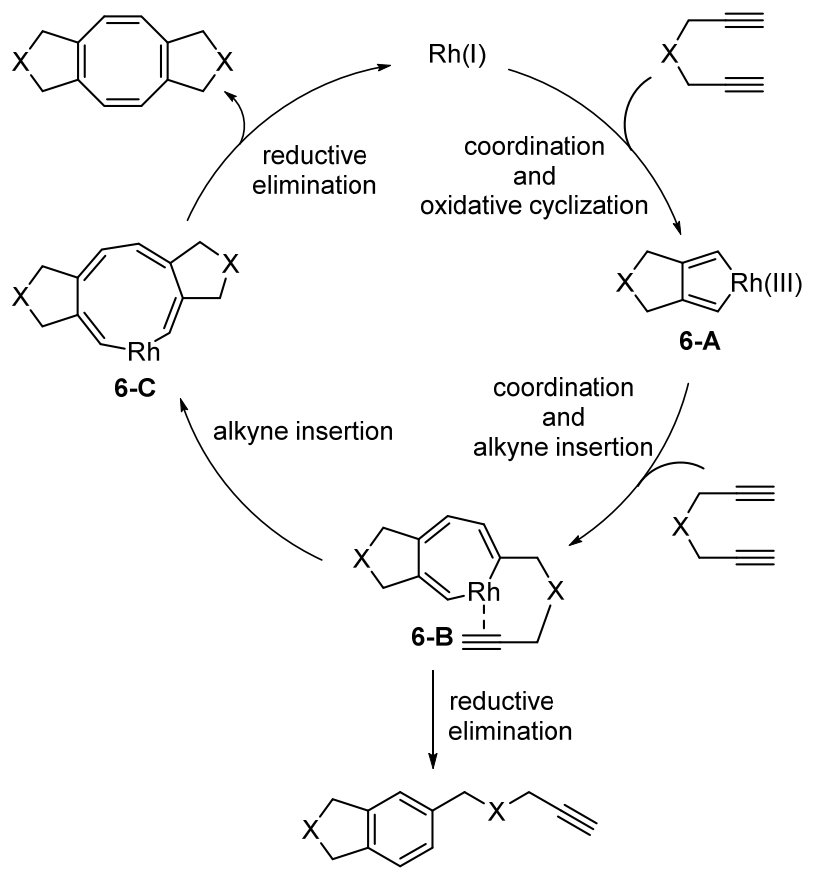

Scheme 6 Rhodium-catalyzed intramolecular $[2+2+2+2]$ cycloaddition of diynes by Croatt

cycloadditions have been developed. 
In 2006, Murakami and coworkers ${ }^{[35]}$ reported a nickel-catalyzed $[4+2+2]$ cycloaddition of diynes with cyclobutanones (Scheme 7, A). They found that both the N-heterocyclic carbene (NHC) ligand IPr and phosphine ligand $\mathrm{P}(n-\mathrm{Bu})_{3}$ were effective for most substrates, with the former being better than the latter in terms of reactivity and selectivity. The authors proposed two plausible mechanisms for their $[4+2+2]$ reaction, which are presented in Figure 7B. In 2012, Fang, Chass, and coworkers ${ }^{[36]}$ did DFT calculations, indicating that pathway $\mathrm{A}$ is more favored than pathway B (Scheme 7, C). The rate-determining steps
(RDS) were the formations of oxanickelacycloheptadiene intermediates for both phosphine and NHC ligands, but the latter is favored by $1.6 \mathrm{kcal} \cdot \mathrm{mol}^{-1}$ in terms of activation free energy. The reason for this different reactivity is due to the strong stability of NHC-Ni complex with electron-density circuit in the structure that could reduce the overall energy of whole potential energy surface. The regiochemistry was also studied by DFT calculations, establishing that carbonyl group prefers to insert into the more substituted $\mathrm{C}-\mathrm{Ni}$ bond (Scheme 7, C).
(A) Nickel-catalyzed [4+2+2] cycloaddition of diynes with cyclobutanones (Murakami)

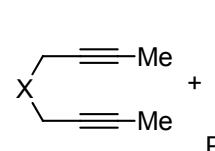

$\mathrm{X}=\mathrm{C}\left(\mathrm{CO}_{2} \mathrm{Me}\right)_{2} \mathrm{Ph}$

7-1<smiles>CC1(c2ccccc2)CC(=O)C1</smiles>
$\mathrm{P}(n-\mathrm{Bu})_{3}(20 \mathrm{~mol} \%), 100{ }^{\circ} \mathrm{C}, 3 \mathrm{~h}, 91 \%$
$\operatorname{IPr}(10 \mathrm{~mol} \%)$, r.t., $1 \mathrm{~h}, 92 \%$<smiles></smiles>

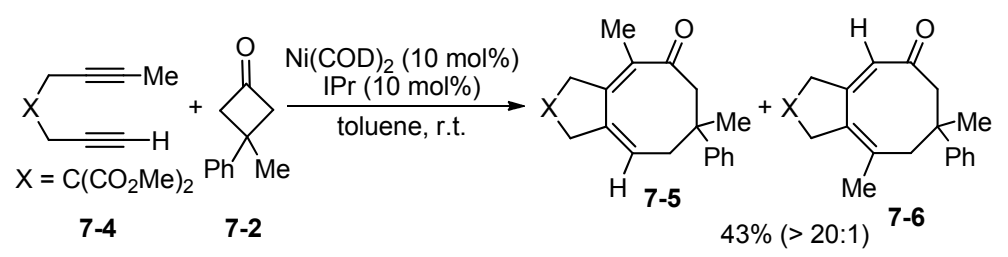

(B) Plausible mechanisms

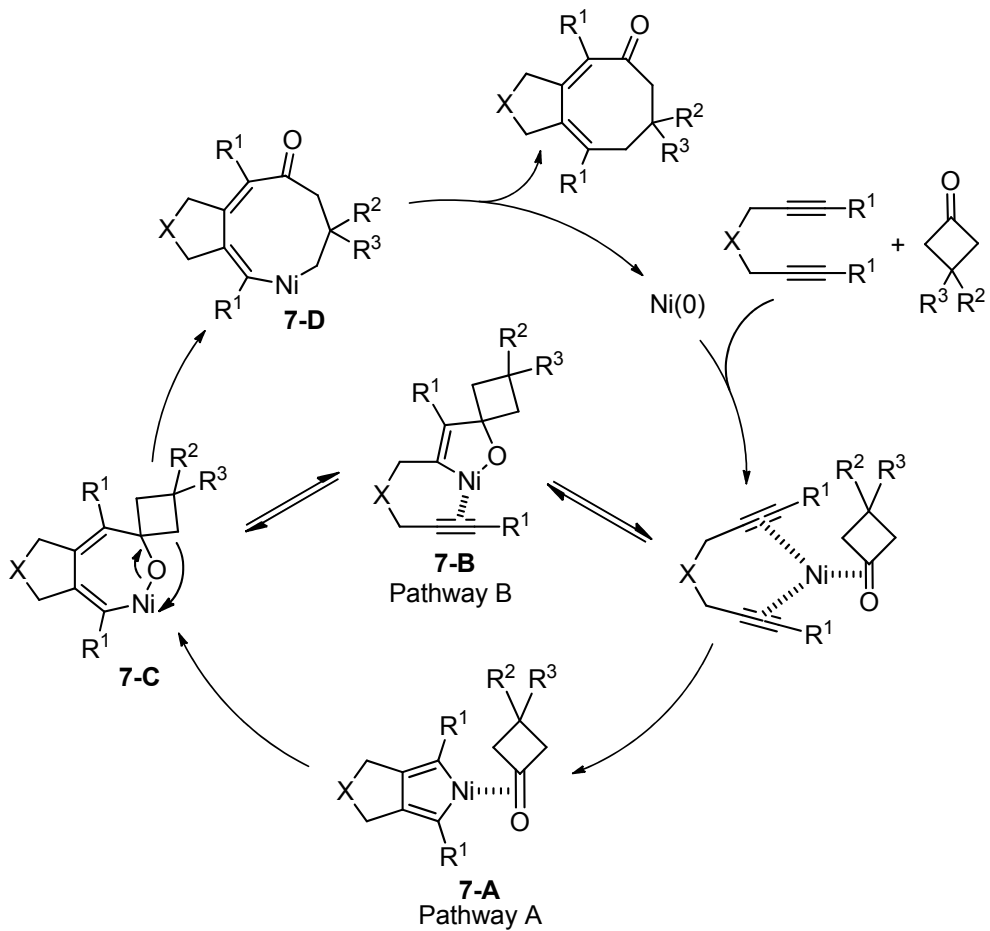

\section{(C) DFT study (Fang and Chass)}

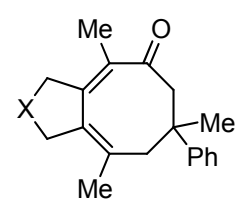

7-3

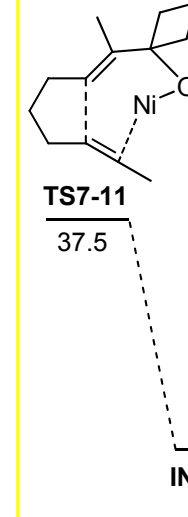<smiles>CC#CN1OC2(CCCC2)C(C)=C2CCCCC21</smiles>

TS7-9

30.6

$\vdots$

0.0

COM7-7
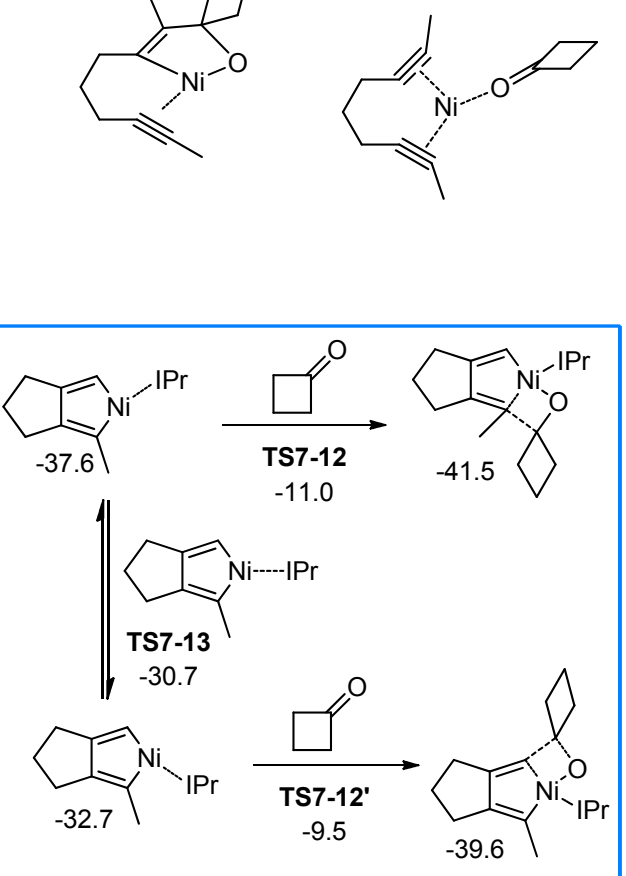

Scheme 7 Nickel-catalyzed [4+2+2] cycloaddition of diynes with cyclobutanones

(A) Experimental results by Murakami, (B) two plausible mechanisms, (C) DFT study by Fang and Chass 
In 2015, Alexanian and coworkers ${ }^{[37]}$ developed a rhodium-catalyzed $[4+2+2]$ cycloaddition of allenedienes 8-1 with allenes 8-2 that furnished fused $c i s-5 / 8$ bicycles 8-3 (Scheme 8). The reactions proceeded smoothly in toluene at $75{ }^{\circ} \mathrm{C}$ by using $2.5 \mathrm{~mol} \%\left[\mathrm{Rh}(\mathrm{COE})_{2} \mathrm{Cl}\right]_{2}$ as the precatalyst and $6 \mathrm{~mol} \%$ racemic MonoPhos as the ligand. Different kinds of substituents on allenedienes and allenes could be tolerated. Substrates containing different tether units (including $\mathrm{C}, \mathrm{N}, \mathrm{O}$ ), substituents on the 1-, 2-, or 3-position of diene moieties and various functional groups can be tolerated and the corresponding cycloadducts were obtained in $36 \% \sim 75 \%$ yields. Asymmetric version of this reaction was also achieved by using $(S)-\mathrm{H}_{8}-$ MonoPhos as the chiral lig- and, and the chiral cycloadducts were obtained in $30 \% \sim 95 \%$ ee. This is the first example of a high enantioselective multicomponent cycloaddition for the synthesis of medium ring carbocycles. A $[4+2]$ cycloaddition occurred as a side reaction when using chiral ligand and the authors found that allene 8-5 played an important role in this side reaction. The $[4+2]$ cycloaddition proceeded in good yields without the presence of allene 8-5, but the enantioselectivity was poor in this case, suggesting that allenes were involved in the enantioselectivity determining step in both the $[4+2+2]$ and $[4+2]$ reactions when it was presented in the reaction system (Scheme 8).

\section{Rhodium catalyzed enantioselective[4+2+2]}

cycloaddition of allenedienes with allenes<smiles>[R]C=C([R])C([R])=CC[X]</smiles>

8-1<smiles>CNp1oc2ccc3ccccc3c2c2c(ccc3ccccc32)o1</smiles>

MonoPhos
$\left[\mathrm{Rh}(\mathrm{COE})_{2} \mathrm{Cl}\right]_{2}(2.5 \mathrm{~mol} \%)$ MonoPhos (6 mol\%)

toluene, $75{ }^{\circ} \mathrm{C}$ $36 \% \sim 75 \%$

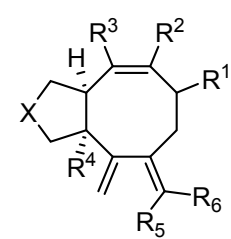

8-3

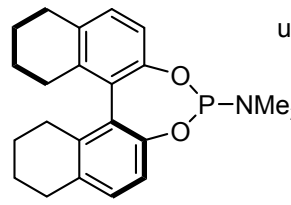

using (S)- $\mathrm{H}_{8}-$ MonoPhos as chiral ligand: $33 \% \sim 60 \%$ yield, $30 \% \sim 95 \%$ ee

(S)- $\mathrm{H}_{8}$-MonoPhos

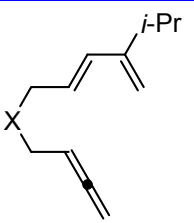

$\left[\mathrm{Rh}(\mathrm{COE})_{2} \mathrm{Cl}\right]_{2}(2.5 \mathrm{~mol} \%)$ (S)- $\mathrm{H}_{8}$-MonoPhos (6 mol\%)

toluene, $60^{\circ} \mathrm{C}$

$\underset{\mathrm{CO}_{2} \mathrm{Bn}}{\longrightarrow}$

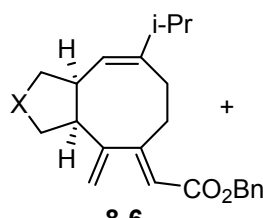<smiles>[X]CC1CC([In])=C[C@H]2CC(=C)[C@H]1C2</smiles>

$\mathrm{X}=\mathrm{C}\left(\mathrm{CO}_{2} \mathrm{Bn}\right)_{2}$

8-5

8-4

\begin{tabular}{ccccc}
\hline Allene & Yield/\% of 8-6 & er & Yield/\% of 8-7 & er \\
\hline- & - & - & 84 & $42: 58$
\end{tabular}

2 equiv

$48-96.5: 3.5$

$37 \quad 77.5: 22.5$

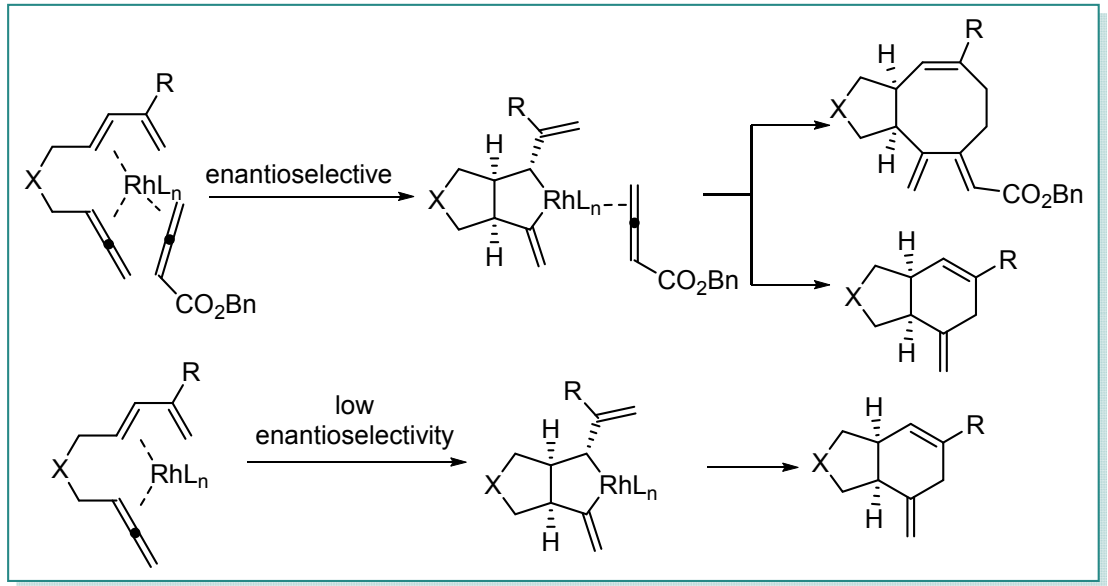

Scheme 8 Rhodium catalyzed enantioselective $[4+2+2]$ cycloaddition of allenedienes with allenes by Alexanian 
In 2002, Gilbertson and coworkers ${ }^{[38]}$ reported the first $[4+2+2]$ cycloaddition of dienynes with allenes catalyzed by a rhodium catalyst to afford bicyclic products containing an eight-membered carbocycle. In 2007, they ${ }^{[39]}$ expanded the scope of substrates for this reaction. In their work, the used catalyst was prepared by $[\mathrm{Rh}(\mathrm{NBD}) \mathrm{Cl}]_{2}$ (1.0 equiv.), $(S, S)$-Me-DuPhos (2.0 equiv.) and $\mathrm{AgSbF}_{6}$ (1.0 equiv.) (Scheme 9, A). The catalyst must be "aged" for the $[4+2+$ 2] cycloaddition. Even though this cycloaddition reaction was very effective, the exact composition of catalyst was not identified. This ambiguity prevented the authors from improving the reactivity and selectivity of the $[4+2+2]$ reaction. In 2014, the authors ${ }^{[40]}$ again screened various ligands, finding that a rhodium-biphosphine monoxide complex 9-1 (Scheme 9, B), which was isolated and characterized by both NMR and single X-ray diffraction, was an effective catalyst for the $[4+2+2]$ cycloaddition of dienynes with alkynes. This new catalyst 9-1 was very active because both acyclic and cyclic dienynes were proved to be successful substrates for the cycloaddition, even tricyclic cycloadduct from substrate 9-7 could also be generated in 97\% yield (Scheme 9, B). If the third component of alkyne was absent in the reaction, a dimerization product 9-6 from dienyne substrate 9-5 was observed, in which one dienyne acted as the six-carbon synthon and another as the two-carbon synthon. A cross-cycloaddition occurred when extra terminal alkynes or acetylenes were added to the reaction system. Internal alkynes would not participate in this reaction. When a chiral rhodium catalyst, $\left[(\mathrm{Rh}(\mathrm{NBD})(S, S)-\mathrm{Me}-\mathrm{BozPhos}) \mathrm{SbF}_{6}\right.$, was used, the enantioselectivity of this reaction was modest ( $\mathrm{ca} .30 \% \mathrm{ee}$ ), but diastereomeric ratio of this reaction was pretty good, which was higher than $20: 1$. A general mechanism, which includes ligand exchange, oxidative cyclometallation, alkyne coordination, insertion and reductive elimination, was proposed by the authors (Scheme 9, C).

Rhodium catalyzed [4+2+2] cycloaddition of dieneynes with alkynes by using biphosphine monooxide ligand

(A) Rhodium catalyzed [4+2+2] cycloaddition of dieneynes with alkynes by using "aged" catalyst
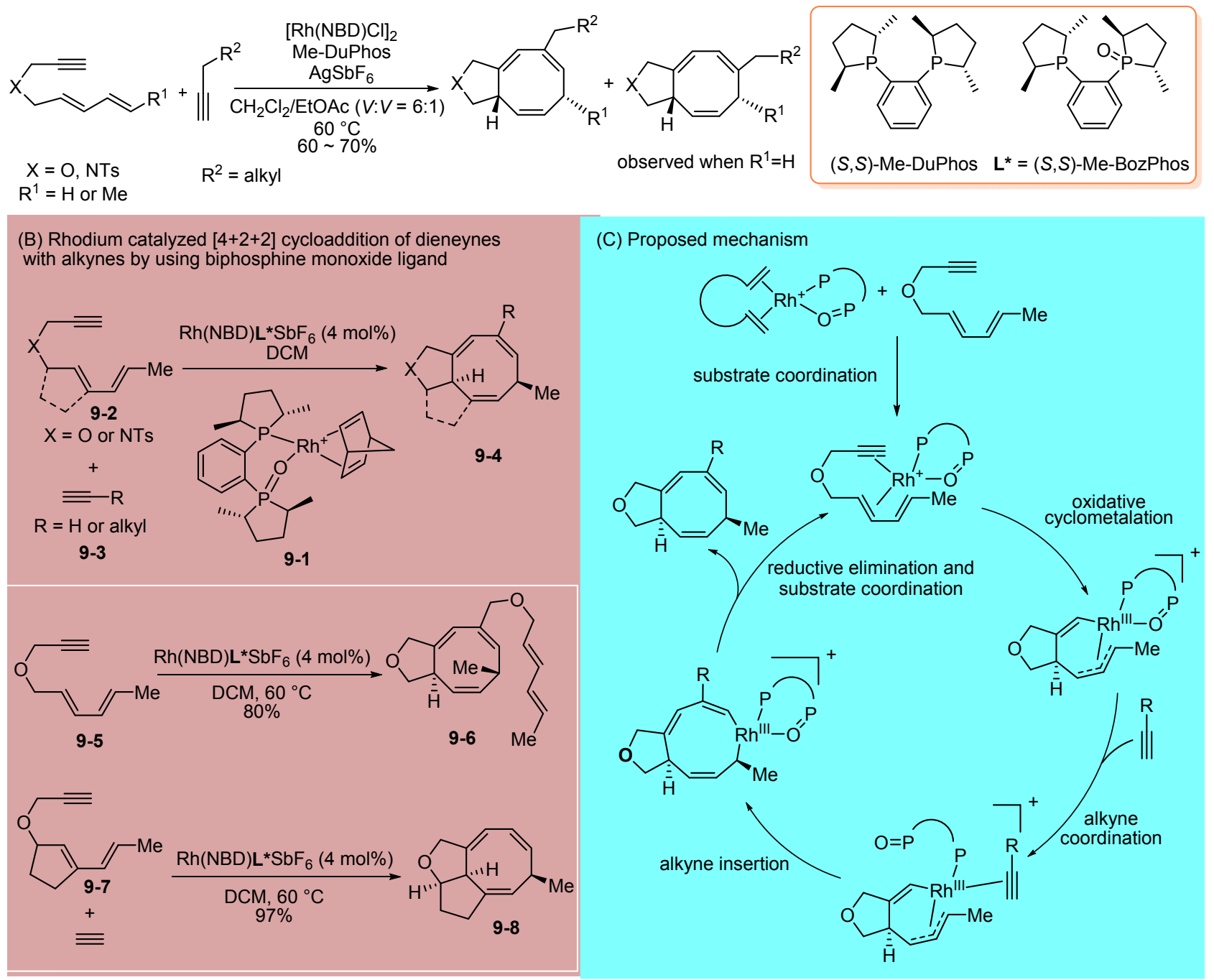

Scheme 9 Rhodium-catalyzed [4+2+2] cycloaddition of dienynes with alkynes by using biphosphine monoxide ligand 
$[4+2+2]$ cycloadditions of enynes with dienes, ${ }^{[41]}$ dienynes with alkynes, ${ }^{[39-40]}$ trienes with alkynes ${ }^{[42]}$ and diynes with dienes ${ }^{[43]}$ have been reported. In 2013, Ogoshi, Sato, and coworkers ${ }^{[44]}$ discovered the first case of $[4+2+$ 2] cycloaddition of dienyne 10-4 with methylenecyclopropane 10-5 (Scheme 10). In their study, nickel-catalyzed $[4+3+2]$ cycloaddition of ethyl cyclopropylideneacetate 10-2 with dienyne 10-1 was achieved to form nine-membered carbocycle 10-3, and only in one case eight-membered ring compound was observed. When 1,8-dienyne substrate and methylenecyclopropane (10.0 equiv.) were treated in toluene at $4{ }^{\circ} \mathrm{C}$, by using $\mathrm{Ni}(\mathrm{COD})_{2}(10 \mathrm{~mol} \%)$ and $\mathrm{PPh}_{3}(20 \mathrm{~mol} \%)$ as catalyst, cycloadduct 10-6 containing eight-membered ring was generated, even though the yield was only $37 \%$. The authors proposed two plausible mechanisms for this $[4+2+2]$ cycloaddition, and pathway A (shown in black) was hypothesized to be more possible than pathway B (shown in blue).

Nickel catalyzed $[4+2+2]$ cycloaddition of dienynes with alkenes

Methodology reported by Ogoshi and Sato: [4+3+2] cycloaddition of dienyne with cyclopropylideneacetate to form nine-membered carbocycle

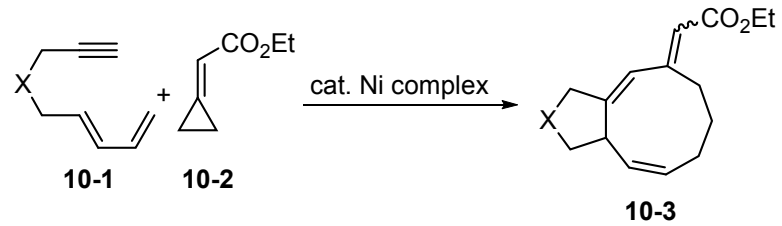

Cyclopropylideneacetate replaced by methylenecyclopropane: the only one $[4+2+2]$ case

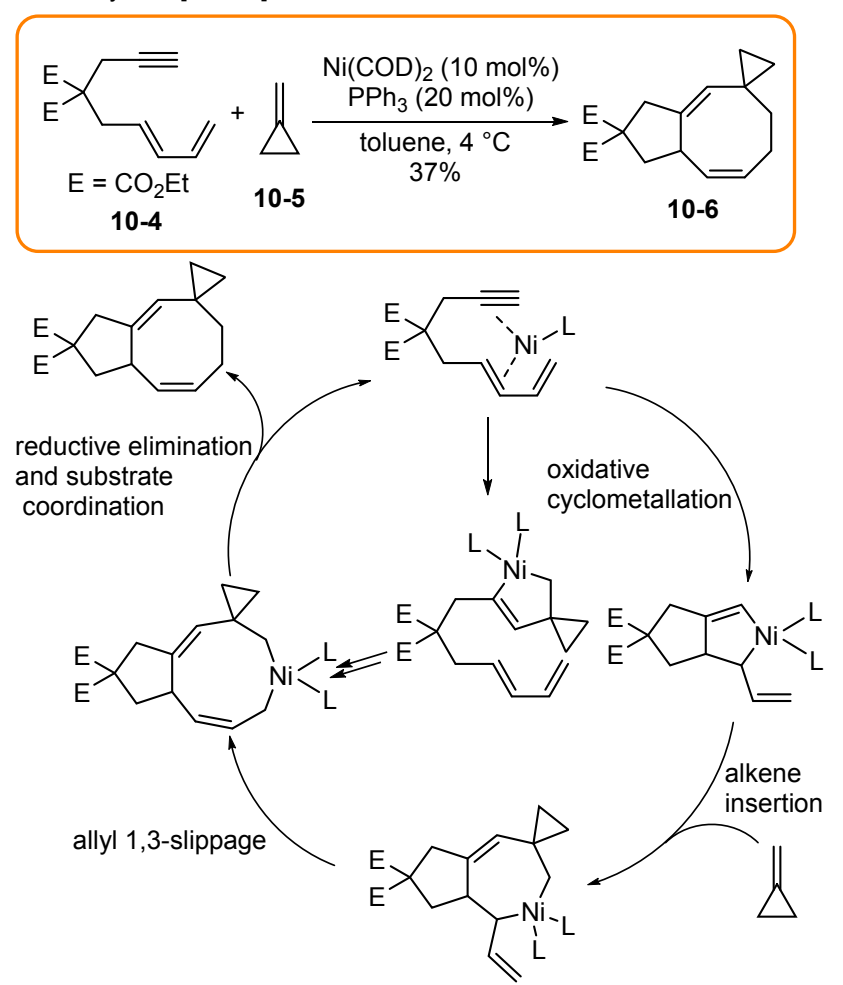

Scheme 10 Nickel-catalyzed $[4+2+2]$ cycloaddition of dienyne with methylene cyclopropane

\section{4 (Formal) [5+3] cycloadditions}

Compared with other types of cycloadditions, $[5+3]$ cycloaddition was rarely reported. In 2016, Echavarren and coworkers reported a gold-catalyzed intramolecular hetero-[3+2+2] cycloaddition of 11-oxo-1,7-allenenes 11-1 to build oxepane-embedded tricyclic molecules. ${ }^{[45]}$ Because three carbon atoms linked the alkene unit and carbonyl unit in the substrates, eight-membered carbocycles were generated at the same time. This reaction can be regarded as a formal "all carbon $[5+3]$ cycloaddition" (Scheme 11, A). The substrates 11-oxo-1,7-allenenes 11-1, when treated with 5 mol\% gold catalyst (Au11-4, or Au11-5, or Au11-6) in DCM at $25{ }^{\circ} \mathrm{C}$, gave the corresponding tricyclic molecules in $40 \% \sim 87 \%$ yields (Scheme $11, \mathrm{~B}$ ). Only in case of using substrate with 1,1-dialkyl-substituted allene, seven-membered ring compound 11-5 was formed (Scheme 11, C). The authors proposed the plausible mechanism (Scheme 11, D). First, the alkene unit in the substrate attacks the gold-activated allene unit to generate carbocation. Then, the carbocation is trapped intra- or intermolecularly by a carbonyl group to form an oxonium cation, which is then followed by a selective Prins reaction to generate an oxo-bridged $5 / 8$ or $5 / 7$ intermediate. Finally, a $[1,2]-\mathrm{H}$ shift of Au carbene gives the final product.

\section{$5 \quad[6+2]$ cycloadditions}

Since the first metal-mediated $[6+2]$ cycloaddition of cycloheptatriene-iron tricarbonyl complex and dimethyl acetylenedicarbornate was reported by Pettit and coworkers in $1974,{ }^{[46]}[6+2]$ cycloadditions have been further developed for the synthesis of various eight-membered carbocycles. These reactions include cycloadditions of 1,3,5- trienes, such as cycloheptatriene (CHT), cyclooctatriene (COT), and cyclooctatetraene (COTT) with alkenes, alkynes and allenes. ${ }^{[47]}$ Different metals could catalyze this transformation, such as $\mathrm{Fe}, \mathrm{Ti}, \mathrm{Mo}, \mathrm{Cr}, \mathrm{Co}$ and Pt. In the past ten years, D'yakonov and coworkers did a series of investigations and developed several $[6+2]$ cycloadditions of different trienes and trienophiles.

The combination of $\mathrm{TiCl}_{4}-\mathrm{Et}_{2} \mathrm{AlCl}$ was proved to be efficient for catalyzing [6+2] cycloadditions of 1,3,5-CHT with 1,3-dienes, norborna-2,5-dienes, and acetylenes, as reported by Tureček and coworkers (Scheme 12, A). ${ }^{[48]}$ In 2011, D'yakonov used the same catalytic system to achieve the cycloaddition of 1,3,5-CHT with allenes (Scheme 12, B). ${ }^{[4]}$ The authors investigated the scope of substrates, finding that both 1-substituted allenes and 1,1-disubstituted allenes could give the desired [6+2] cycloadducts when reacted with CHT. It is worthy to mention that, cyclic allenes worked well for this reaction, generating the corresponding fused bicyclic products containing an eight-membered ring. Besides, $\alpha, \omega$-diallenes and $\alpha, \omega$ diynes could also react with 1,3,5-CHT to afford bis(endobicyclo[4.2.1]nona-2,4-dienes) and bis(trimethylsilyl-endobicyclo[4.2.1]nona-2,4,7-trienes) with polymethylene linkers. $^{[50]}$ 


\section{Gold catalyzed formal [5+3] cycloaddition of 11-oxo-1,7-allenenes}

(A) Gold catalyzed formal [5+3] cycloaddition<smiles>[Y]C/C=C(/C)CCC([R])=O</smiles>

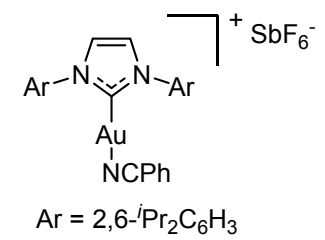

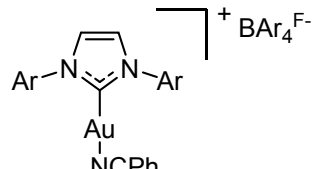
N'CPh

$$
\text { Au11-4 }
$$

$$
\begin{gathered}
\mathrm{Ar}= \\
\text { Au11-6 } \\
\text { Au }
\end{gathered}
$$

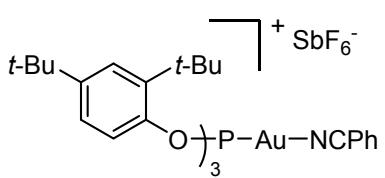

Au11-6

(B) Scope of substrates to generate $5 / 8$ bicycles

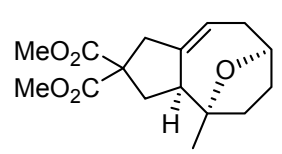

Au11-4, $d r=3: 1,42 \%$ Au11-5, $d r=3: 1,46 \%$ Au11-6, $d r=1: 1,79 \%$

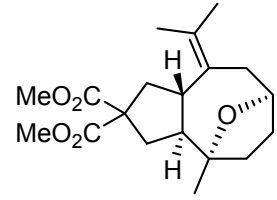

Au11-4, 78\%

Au11-6, $d r=3: 1,88 \%$

(C) 1,1-Disbustituted allene to form seven-membered compounds<smiles>[X]C/C=C(/C)CCC(=O)/C=C\C(=O)OCC</smiles>

$\mathrm{X}=\mathrm{C}\left(\mathrm{CO}_{2} \mathrm{Me}\right)_{2}$

11-4

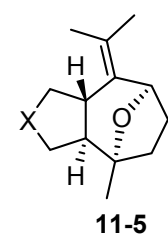

Au11-4, $15 \mathrm{~min}, 78 \%$ Au11-6, 2 min, 3:1, 88\%

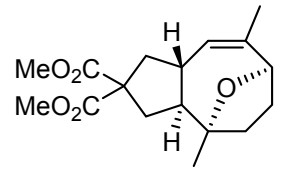

Au11-4, 46\%; Au11-6, 40\%

(D) Proposed mechanism

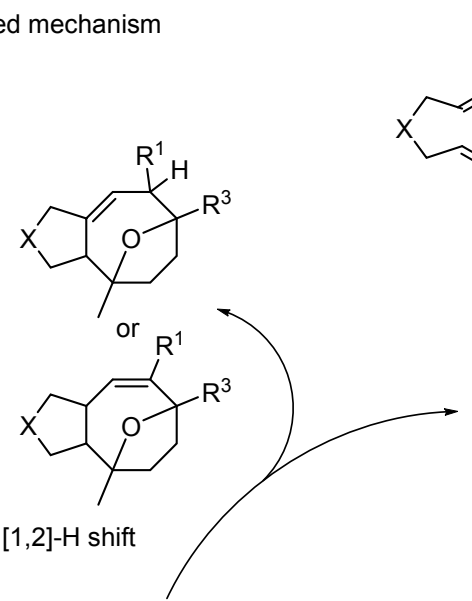<smiles>[X]CC=C=C([R])[R]</smiles>

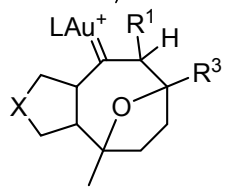

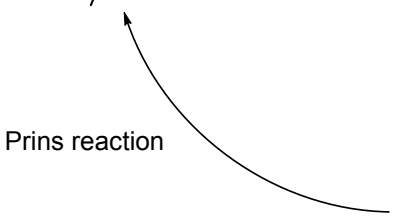<smiles>[Y]C/C=C(/C)CCC([R])=O</smiles>
$R^{3}$

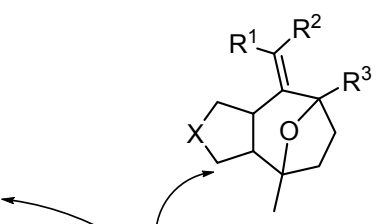
allene-ene cyclization

$[1,2]-\mathrm{H}$ shift

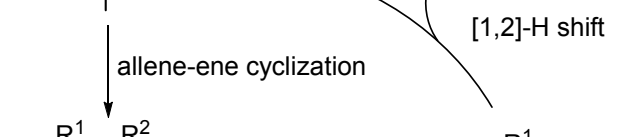<smiles>[R]C(=O)CCC(C)C1CCC1C([Y10])=C([R])[R]</smiles>

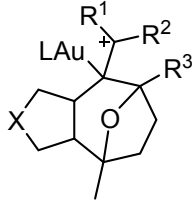
nucleophilic attack

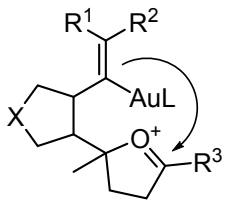

Prins reaction

Scheme 11 Gold-catalyzed formal [5+3] cycloaddition of 11-oxo-1,7-allenenes 
(A) Ti(III) catalyzed [6+2] cycloaddition of

1,3,5-CHT with 1,3-dienes or alkynes (Turecek)

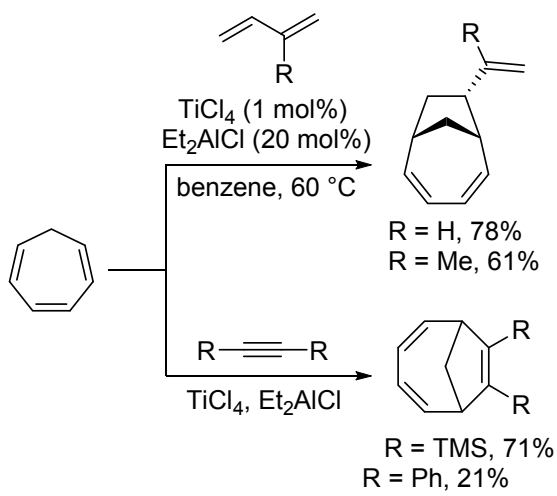

(B) Ti(III) catalyzed [6+2] cycloaddition of 1,3,5-CHT with allenes: D'yakonov

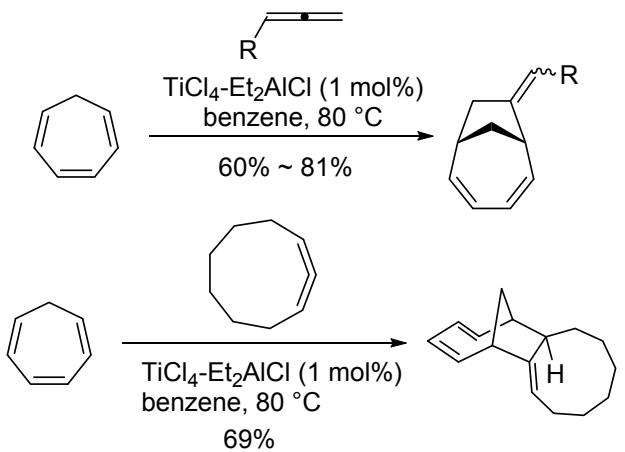

(C) $\mathrm{Ti}(\mathrm{acac})_{2} \mathrm{Cl}_{2}-\mathrm{Et}_{2} \mathrm{AlCl}$ catalyzed [6+2] cycloaddition of 1,3,5-CHT with propargyl amines, alkynes, allenes

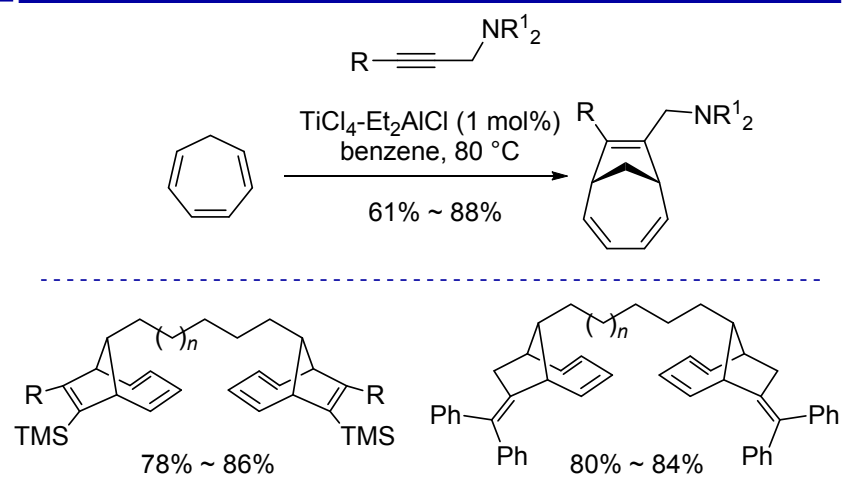

(D) Plausible mechanism of Ti(III) catalyzed [6+2] cycloaddition of 1,3,5-CHT with alkynes or allenes

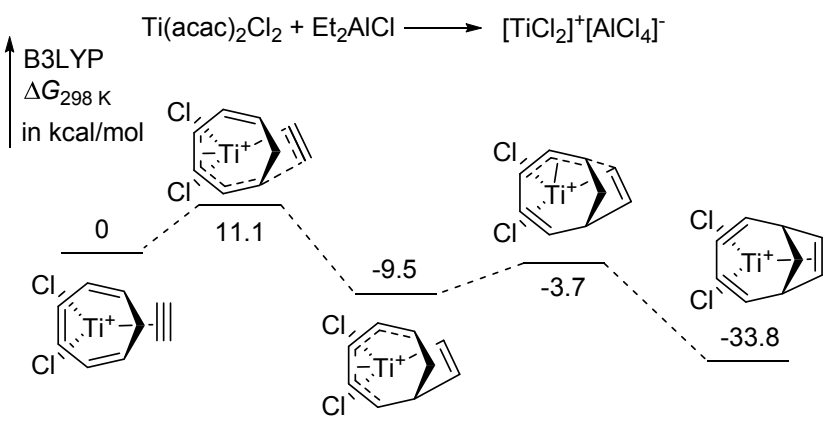

Scheme 12 Ti(III)-catalyzed [6+2] cycloadditions of 1,3,5-CHT with unsaturated carbon-carbon bond to construct eight-membered carbocycles

In 2013, D'yakonov and coworkers ${ }^{[51]}$ improved this [6+ 2] transformation (Scheme 12, C). $\mathrm{Ti}(\mathrm{acac})_{2} \mathrm{Cl}_{2}$ or $(\mathrm{RO})_{2} \mathrm{TiCl}_{2}$ was used to replace $\mathrm{TiCl}_{4}$, and the reaction became more efficient, as judged by their observations that not only allenes, but also disubstituted acetylenes, propargyl amines, norbornadienes, and isoprene could be employed as two-carbon synthons in the $[6+2]$ cycloadditions. It should be noted that, only $\mathrm{Ti}(\mathrm{acac})_{2} \mathrm{Cl}_{2}-\mathrm{Et}_{2} \mathrm{AlCl}$ could catalyze the [6+2] cycloaddition of 1,3,5-CHT with propargyl amines. $\mathrm{TiCl}_{4}$ or $(\mathrm{RO})_{2} \mathrm{TiCl}_{2}$ as catalyst in combination with the organoaluminum reducing agents cannot give the desired cycloadducts for this $[6+2]$ reaction. In the follow-up work, the authors studied the scope of substrates of this reaction and proposed a plausible mechanism based on their DFT calculations (Scheme 12, D) ${ }^{[52]}$ Firstly, the Ti(IV) is reduced by organoaluminum to generated $\mathrm{TiCl}^{2+}$, a Ti(III) species. Then, oxidative cyclometallation of CHT-Ti coordinated complex with alkyne or allene takes place. After that, reductive elimination reaction gives rise to the cycloadduct-Ti(III) complex. Finally, ligand exchange reaction releases the product and catalyst which then enters the next catalytic cycle.

Not only Ti catalyst but also cobalt complex could catalyze $[6+2]$ cycloadditions of CHT with unsaturated carbon-carbon bonds (Scheme 13). In 2005, Buono and coworkers $^{[53]}$ reported the first cobalt-catalyzed $[6+2]$ cycloaddition of CHT with alkynes to construct eight-membered carbocycles. A catalytic system consisting of $\mathrm{CoI}_{2}$ (dppe), $\mathrm{Zn}$ and $\mathrm{ZnI}_{2}$ was used to realize the reaction. A Co(I) species, which was generated from the reduction of $\mathrm{Co}$ (II) by $\mathrm{Zn}$, was proposed as the active catalyst. In 2006, they reported similar cycloadditions that COTT or COT could react with alkynes to give bicyclo[4.2.2]deca2,4,7,9-tetra(tri)enes. ${ }^{[54]}$ By using the same catalytic system, Buono et al. realized the cycloaddition of $\mathrm{CHT}$ with allene in $2011 .^{[55]}$ In this case, only $E$-isomers were observed in the reaction (Scheme 13, A).

Inspired by Buonos' work, D'yakonov and coworkers ${ }^{[56]}$ expanded the scope of substrates. In 2015 and 2016, they reported the $[6+2]$ cycloaddition of COTT with allenes under the same conditions as that reported by Buono in 2005 (Scheme 13, B). The reaction gave the corresponding products in good yields. In 2018, D'yakonov et al. disclosed more results about $[6+2]$ cycloaddition of COTT with alkynes (or diynes) catalyzed by $\mathrm{Co}(\mathrm{I})$. In this work, $\mathrm{Co}(\mathrm{acac})_{2}$ was used to replace $\mathrm{CoI}_{2}$ (Scheme 13, C). ${ }^{[57]}$ In 2020 , [6 +2] cycloaddition of azepines with alkynes or dialkynes was also reported (Scheme $13, \mathrm{D}){ }^{[58]}$

In 2011, Sato and coworkers ${ }^{[59]}$ reported an intramolecular rhodium-catalyzed $[6+2]$ cycloaddition of 4-allenals with alkynes or alkenes (Scheme 14, A). When the substrate, alkyne-4-allenal 14-1 was treated with $10 \mathrm{~mol} \%$ 
(A) Co(I) catalyzed [6+2] cycloaddition of CHT or COTT with alkynes or allenes

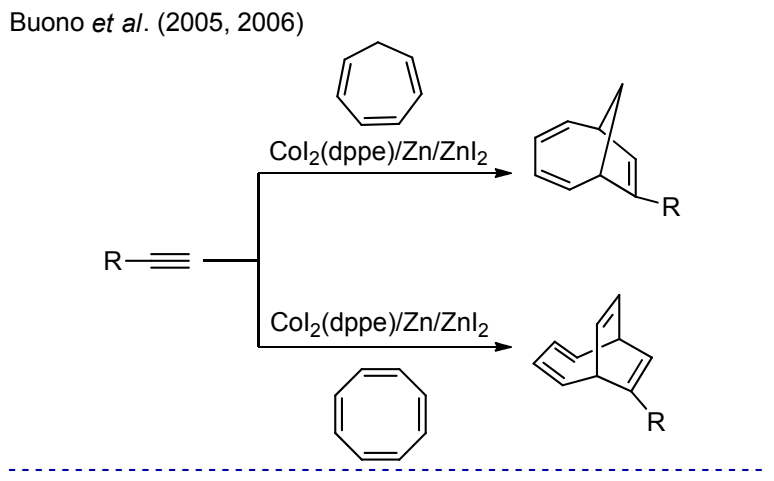

Buono et al. (2011)
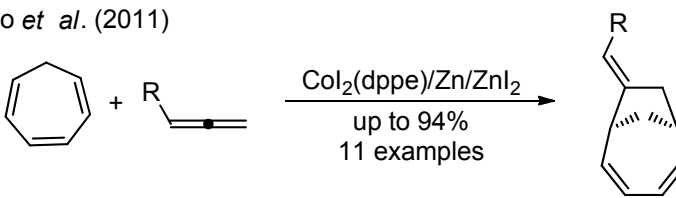

Only E-isomer

(B) Co(I) catalyzed [6+2] cycloaddition of COTT with allenes

D'yakonov et al. (2015)

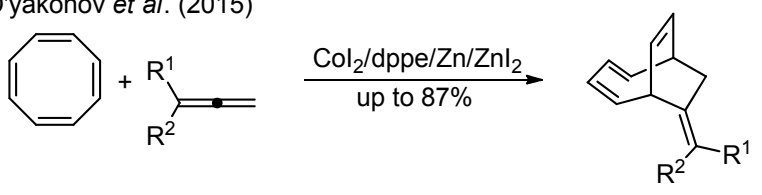

(C) More investigation for cycloaddition of COTT with alkynes or dialkynes (D'yakonov)

D'yakonov et al. (2018)

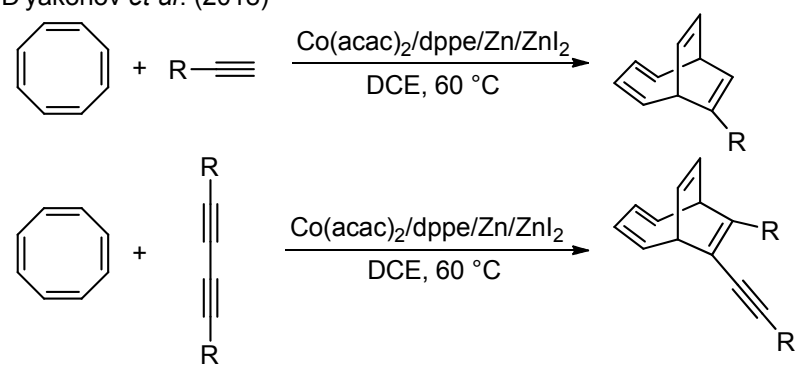

(D) Cycloaddition of azepines with alkynes (D'yakonov)

D'yakonov et al. (2020)
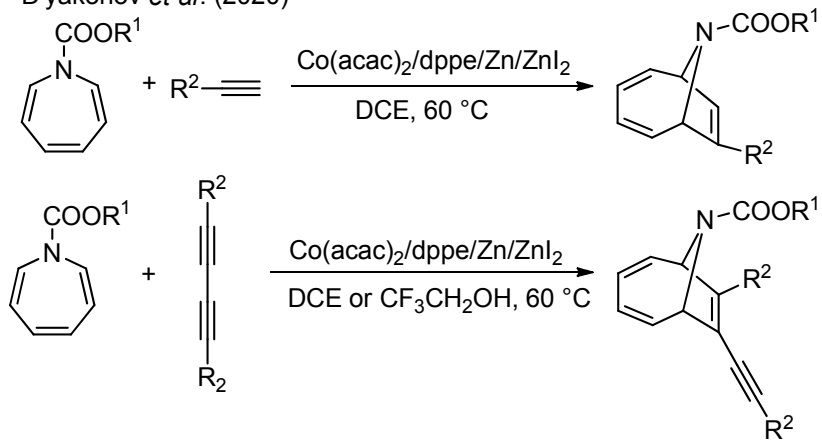

Scheme $13 \mathrm{Co}(\mathrm{I})$-catalyzed [6+2] cycloadditions of CHT or COTT with alkynes or allenes by Buono and D'yakonov
$[\mathrm{Rh}(\mathrm{IMes})(\mathrm{COD})] \mathrm{ClO}_{4}$, the [6+2] cycloaddition occurred to generate $5 / 8$ product $14-2$ or $6 / 7$ product $14-3$, or both, depending on the reaction conditions. It was also found that cyclization of enantiomerically enriched $(S)$-14-1 $(94 \%$ ee $)$ gave cyclic ketone derivative $(S)$-14-2 in a high yield, with reasonable chirality transfer from substrate to product $(86 \%$ $e e)$. A plausible mechanism was proposed by the authors (Scheme 14, B). First, intermediate 14-C is formed through a $\mathrm{Rh}(\mathrm{I})$-catalyzed hydroacylation. Then intermediate 14-E is generated by a $\pi$-allyl slippage. Finally, alkyne or alkene insertion and reductive elimination take place to give the final bicyclic product. In 2012, Sato et al.$^{[60]}$ developed an intermolecular version of this $[6+2]$ cycloaddition by applying $[\mathrm{Rh}(\mathrm{SIMes})(\mathrm{COD})] \mathrm{ClO}_{4}$ instead of $[\mathrm{Rh}$ (IMes)(COD) $] \mathrm{ClO}_{4}$ as the catalyst, and more than 20 substrates underwent the desired reactions in good reaction yields (Scheme 14, C).

In 2014, Bi and coworkers ${ }^{[6]]}$ proposed a new mechanism based on their DFT calculations (Scheme 15). Their DFT calculations were initially planned to investigate the regioselectivity of Sato's [6+2] reaction: when $\mathrm{Rh}\left(\mathrm{PPh}_{3}\right)_{3} \mathrm{Cl}$ was used, the product was $5 / 8$ bicycle, whereas using $\mathrm{Rh}$ (dppe) $\mathrm{ClO}_{4}$ as the catalyst, 6/7 bicycle was the only product formed (Scheme 14, A). The DFT results showed that, when $\mathrm{Rh}\left(\mathrm{PPh}_{3}\right)_{3} \mathrm{Cl}$ was used as the catalyst, the overall activation barrier was $35.8 \mathrm{kcal} \cdot \mathrm{mol}^{-1}$, which is too high for this reaction to occur. A new mechanism involving $\mathrm{H}$-migration from the metal to allenic carbon was then proposed by $\mathrm{Bi}$ and coworkers, but the overall activation barrier from $\mathrm{R}+\mathrm{RhL}_{2}$ to TS15-B was also as high as 40.6 $\mathrm{kcal} \cdot \mathrm{mol}^{-1}$. Therefore, Bi and coworkers proposed that a trace amount of water in the solvent could aid H-migration to reduce the activation energy, which was inspired by studies of $\mathrm{Yu}$ and other researchers' of water-catalyzed proton shift mechanisms. ${ }^{[62]}$ DFT results showed that, the new mechanism, in which $\mathrm{H}_{2} \mathrm{O}$ and $\mathrm{Cl}$ both act as the mediators to help the hydrogen transfer is reasonable. As shown in Scheme 15, the overall barrier via TS-15-C is 29.2 $\mathrm{kcal} \cdot \mathrm{mol}^{-1}$. Besides, the authors discovered that a trace amount of water also played an important role for the formation of 6/7 bicycles when the $\mathrm{Rh}(\mathrm{dppe}) \mathrm{ClO}_{4}$ was used as catalyst. More details of mechanistic insights can be found in their original study.

In 2013, Mascareñas, López, and coworkers ${ }^{[63]}$ reported a gold(I)-catalyzed intermolecular formal $[6+2]$ cycloaddition of allenamides with carbonyl-tethered alkenes. Inspired by previously reported gold-catalyzed [2+2] cycloaddition of allenamides with alkenes, ${ }^{[64]}$ the authors designed a cascade cycloaddition process (Scheme 16, A). It is proposed that the allenamide is activated by $\mathrm{Au}(\mathrm{I})$, which is followed by alkene addition. Then, a cascade cyclization leads to the final oxa-bridged medium-size carbocycles. The ring size in the product (seven-, eight- or ninemembered ring) is determined by the length of the linker between alkene moiety and carbonyl moiety. When the alkene and carbonyl is tethered by three carbons, a formal $[6+2]$ cycloaddition occurs, giving the corresponding 


\section{(A) $\mathrm{Rh}(\mathrm{I})$ catalyzed intramolecular [6+2] cycloaddition of 4-allenals with alkynes or alkenes (Sato)}

Reaction condition optimization

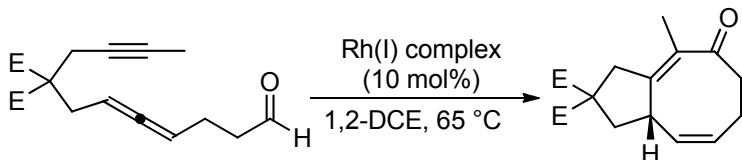

14-1, $\mathrm{E}=\mathrm{CO}_{2} \mathrm{Me}$
14-2<smiles>CC1=C2CC(F)(F)CC=C2C=CCC1O</smiles>

14-3

\begin{tabular}{ccccc}
\hline & & & \multicolumn{2}{c}{ Yield/\% } \\
\cline { 4 - 5 } Entry & \multicolumn{1}{c}{$\mathrm{Rh}(\mathrm{I})$ complex } & $\mathrm{Time} / \mathrm{h}$ & $\mathbf{1 4 - 2}$ & $\mathbf{1 4 - 3}$ \\
\hline 1 & {$\left[\mathrm{Rh}(\mathrm{IMes})(\mathrm{COD}) \mathrm{ClO}_{4}\right.$} & 2 & 76 & - \\
2 & $\mathrm{Rh}\left(\mathrm{PPh}_{3}\right)_{3} \mathrm{Cl}$ & 5 & 72 & - \\
3 & {$\left[\mathrm{Rh}(\mathrm{dppe}) \mathrm{ClO}_{4}\right.$} & 1 & - & 27 \\
\hline
\end{tabular}

Scope of substrates

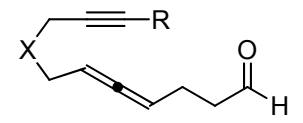

$\mathrm{X}=\mathrm{O}, \mathrm{NTs}, \mathrm{C}\left(\mathrm{CO}_{2} \mathrm{Me}\right)_{2}$

$\mathrm{C}\left(\mathrm{CH}_{2} \mathrm{OBn}\right)_{2}$<smiles>CC#CCCC(F)(F)CC=CCCCCC</smiles>

$\mathrm{E}=\mathrm{CO}_{2} \mathrm{Me}$

14-6<smiles>[R]C(=C)CC(F)(F)CC=CCCCC=O</smiles>
14-8<smiles>CC#CCC(F)(F)CC=CCCC=O</smiles>

$\mathrm{E}=\mathrm{CO}_{2} \mathrm{Me}$

(S)-14-1 (94\% ee)

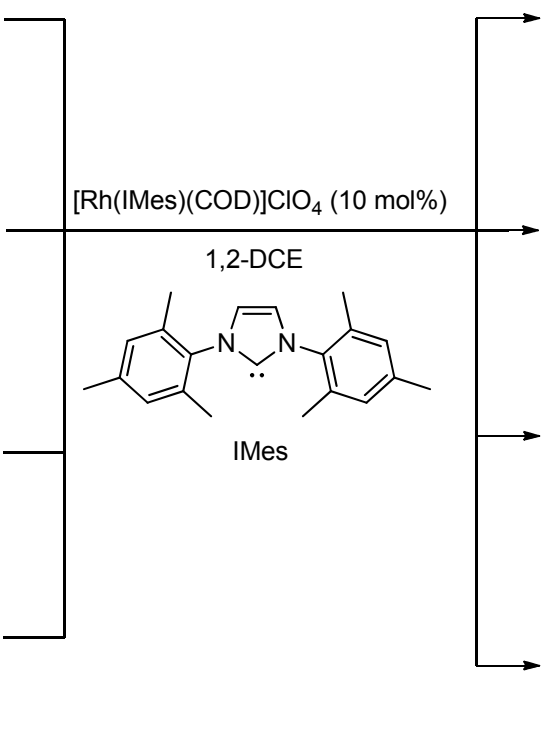

(B) Plausible mechanism

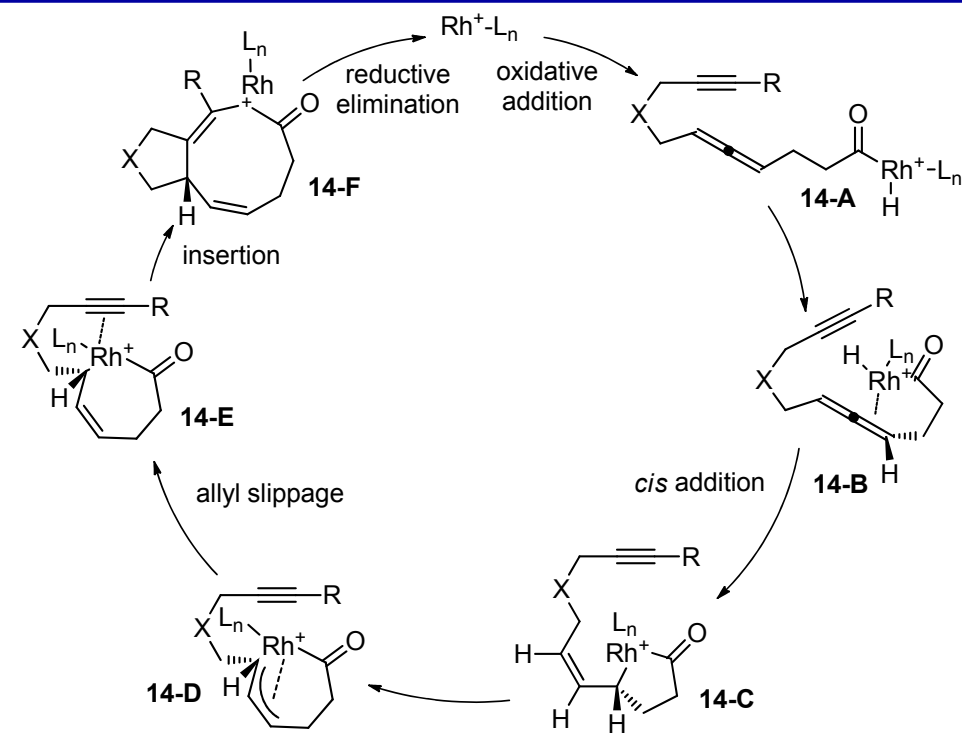

(C) $\mathbf{R h}(\mathrm{I})$ Catalyzed intermolecular [6+2] cycloaddition
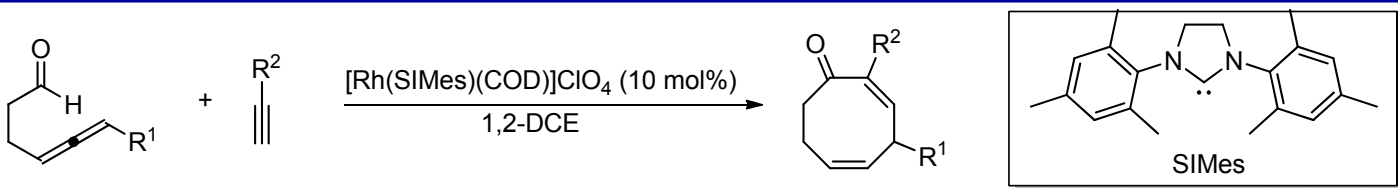

Scheme 14 Rh(I)-catalyzed intra- and intermolecular [6+2] cycloaddition of 4-allenals with alkynes or alkenes 


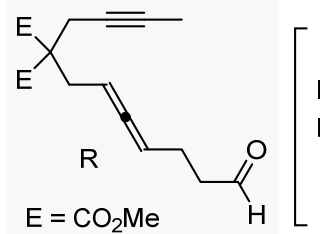

$[\mathrm{Rh}]=\mathrm{RhClL}=\mathrm{RhCl}\left(\mathrm{PH}_{3}\right)$<smiles></smiles>

TS-15-B

(40.6)<smiles>CC#CCC(F)(F)CC=C1CCC(=O)C1</smiles>

TS-15-A

(35.8)

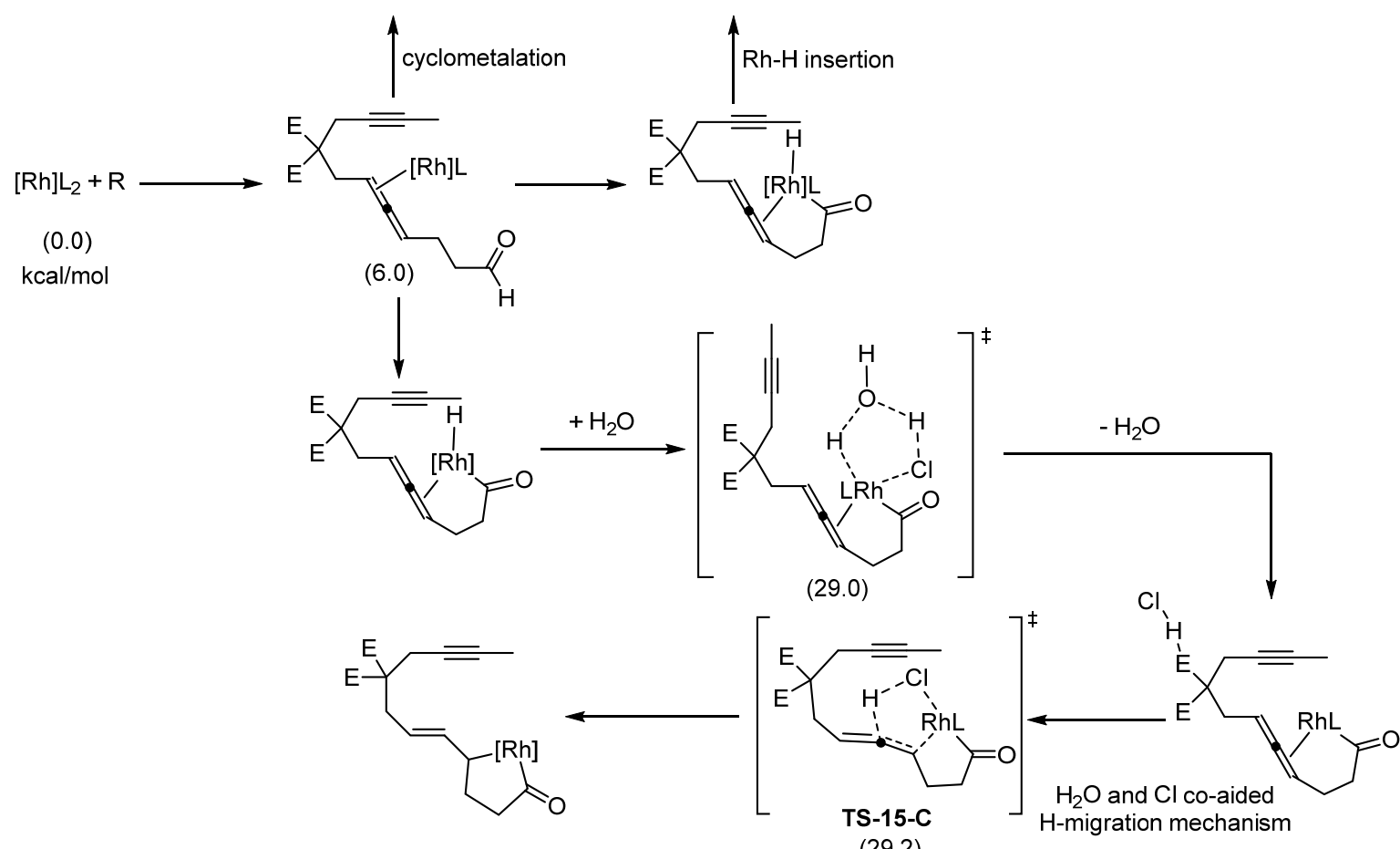

(29.2)

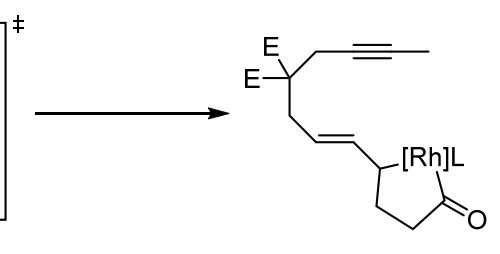

Scheme 15 DFT study of Rh(I) catalyzed [6+2] cycloaddition of 4-allenal with alkyne

eight-membered carbocycles in good yields. When a chiral gold catalyst was used, this reaction was developed to its asymmetric version (Scheme 16, B).

In addition to the above mentioned reaction development for metal-catalyzed $[6+2]$ cycloadditions, there was also an application of a previous $[6+2]$ reaction in natural product synthesis. Since 1991, Rigby and coworkers developed several Cr-involved [6+2] cycloadditions of CHT with alkynes to synthesize bridged eight-membered carbocycles $^{[65]}$ and applied them to natural product synthesis ${ }^{[66]}$. In 2015, Misra, Rigby and coworkers ${ }^{[67]}$ reported a formal synthesis of Echinopines A and B by using [6+2] cycloaddition of $\mathrm{Cr}(\mathrm{CO})_{3}-\mathrm{CHT}$ with alkyne as a key step to synthesize 17-1 with the [4.2.1] bicyclic skeleton (Scheme 17). Then a sequential radical cyclization process was used to reach 17-3, from which the final natural products could be synthesized by using literature transformations. ${ }^{[68]}$

\section{$6 \quad[7+1]$ cycloadditions}

In 2011, Yu and coworkers ${ }^{[69]}$ developed the first $[7+1]$ cycloaddition of buta-1,3-dienylcycloprapnes (BDCPs) 18-3 with carbon monoxide to construct substituted cy- clooctadienones 18-4 and 18-5, by using $\left[\mathrm{Rh}(\mathrm{CO})_{2} \mathrm{Cl}\right]_{2}$ as the catalyst (Scheme 18). This work was inspired by rhodium catalyzed $[5+2+1]$ cycloaddition of ene-vinylcyclopropanes (ene-VCPs) with carbon monoxide, which was also discovered by the $\mathrm{Yu}$ group in 2007. ${ }^{[70]}$ They proposed that BDCPs undergoes cyclometallation and $\mathrm{C}-$ $\mathrm{C}$ cleavage of the cyclopropane to give eight-membered rhodacycle 18-B. Then $\mathrm{CO}$ insertion and reductive elimination give rise to the $[7+1]$ products. As expected, when BDCPs 18-3 were treated with $\left[\mathrm{Rh}(\mathrm{CO})_{2} \mathrm{Cl}\right]_{2}(10 \mathrm{~mol} \%)$ in 1,4-dioxane at $85 \sim 95{ }^{\circ} \mathrm{C}$ under carbon monoxide atmosphere, the corresponding eight-membered cycloadducts were generated. In the $[7+1]$ cycloaddition, the conjugated products 18-4 were the major products, which were isomerized from the initially generated non-conjugated products 18-5 from the $[7+1]$ cycloaddition, as shown by the proposed mechanism in Scheme 18. It was noteworthy that 1 -substituted BDCPs did not give the $[7+1]$ cycloadducts but generated substituted cyclohexenones, which were generated from the $[5+1]$ cycloaddition of the VCP moiety of BDCPs with carbon monoxide. ${ }^{[71]}$ 
(A) Au(I) Catalyzed intermolecular [2+2] cycloaddition of allenamides with alkenes and designed [6+2] cylcloaddition

Previous $\mathrm{Au}(\mathrm{I})$ catalyzed [2+2] cycloaddition of allenamides with alkenes

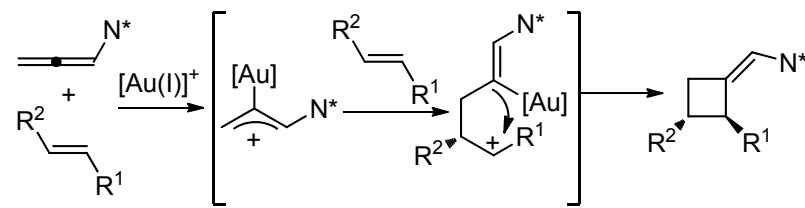

Designed cascade cycloaddition process (Mascareñas and López)

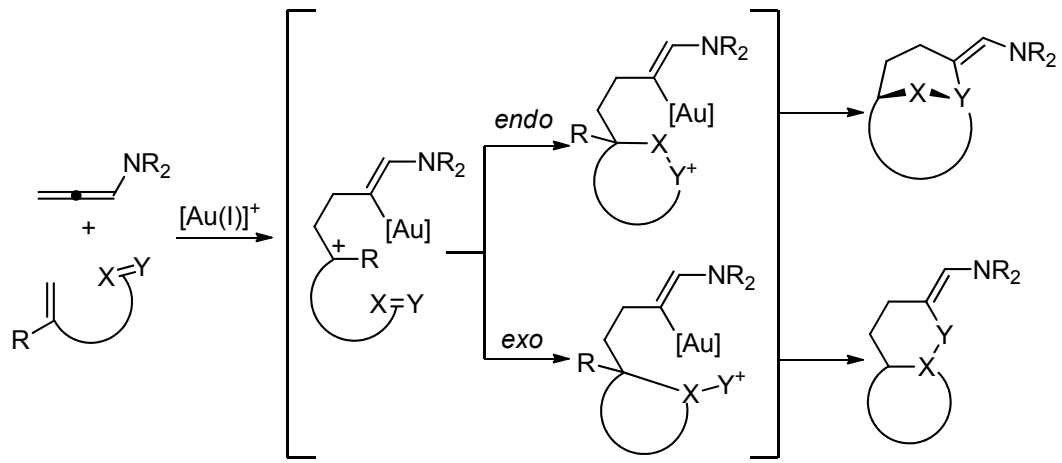

(B) Au(I) Catalyzedintermolecular [6+2] cycloaddition of allenamides with carbonyl-tethered alkenes

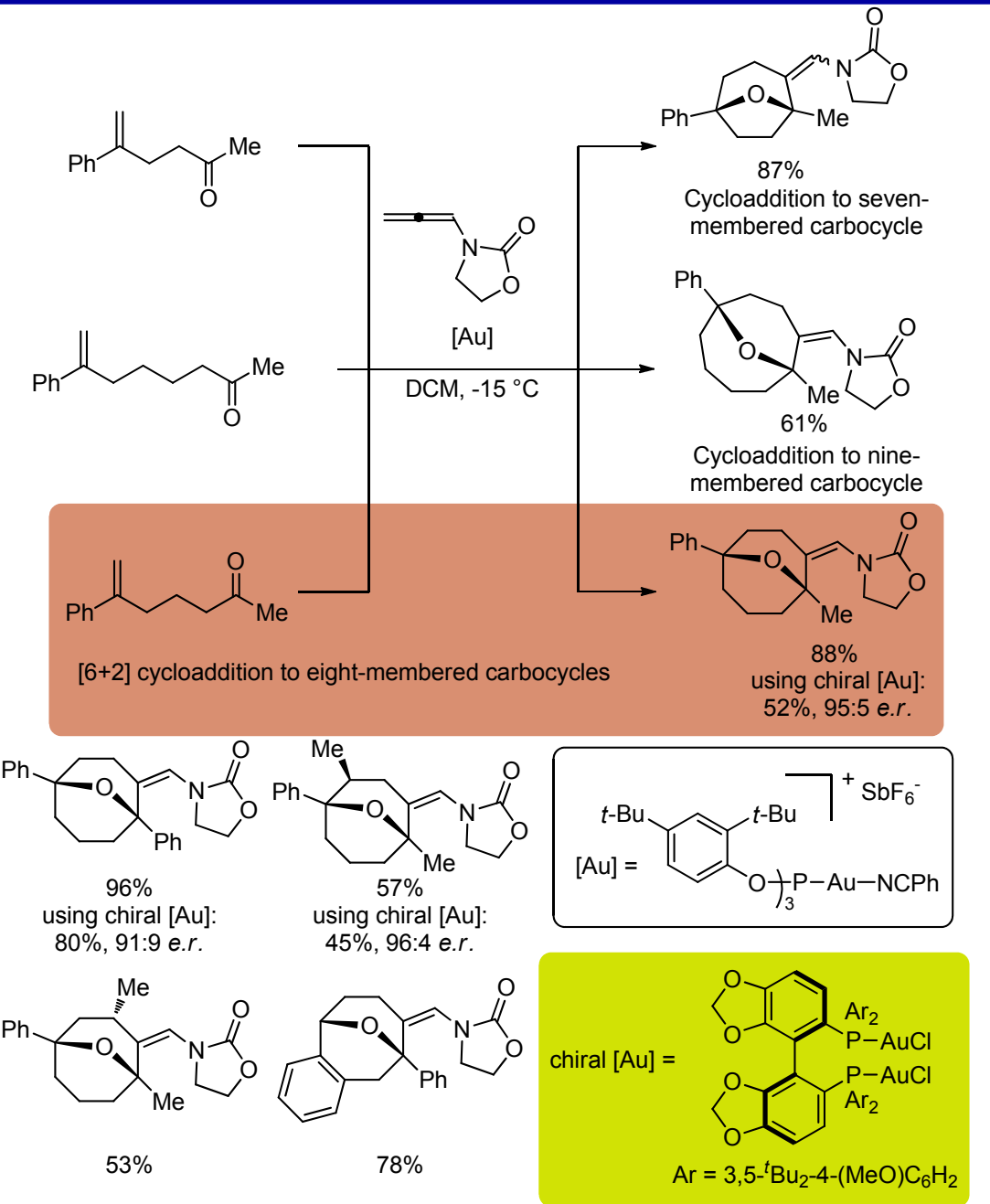

Scheme $16 \mathrm{Au}(\mathrm{I})$ catalyzed intermolecular [6+2] cycloaddition of allenamindes with enones 

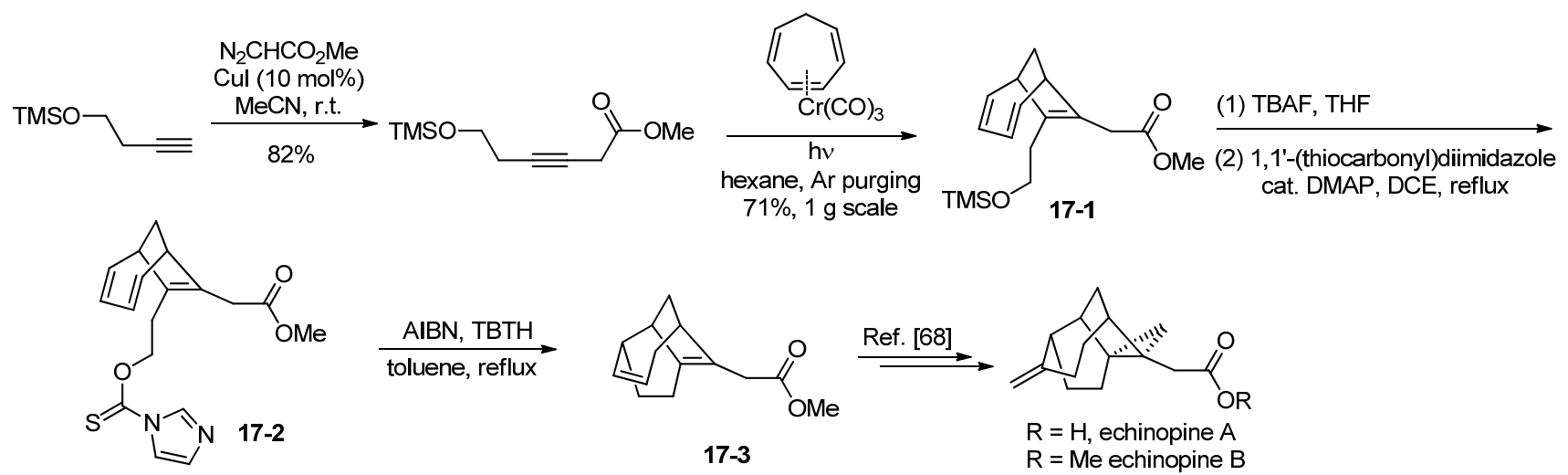

Scheme 17 Formal synthesis of echinopines A and B using [6+2] cycloaddition as a key step

\section{Rhodium catalyzed [7+1] cycloaddition} of BDCPs with CO

(A) Reaction design of [7+1] cycloaddition

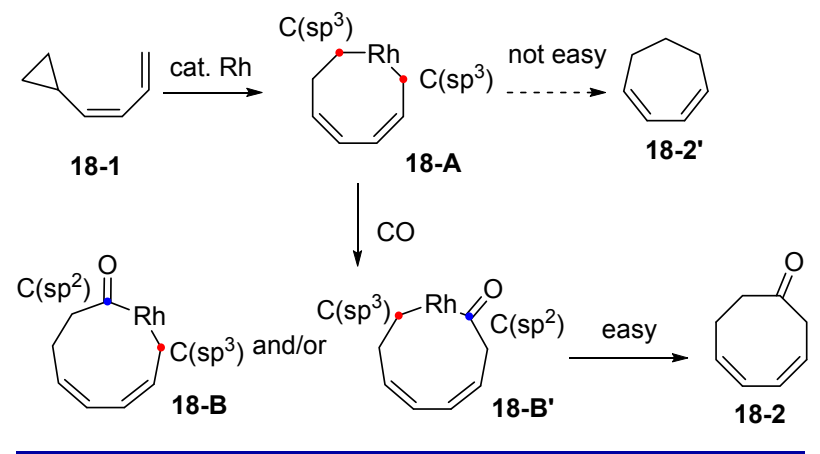

(B) $[7+1]$ cycloaddition of BDCPs with CO

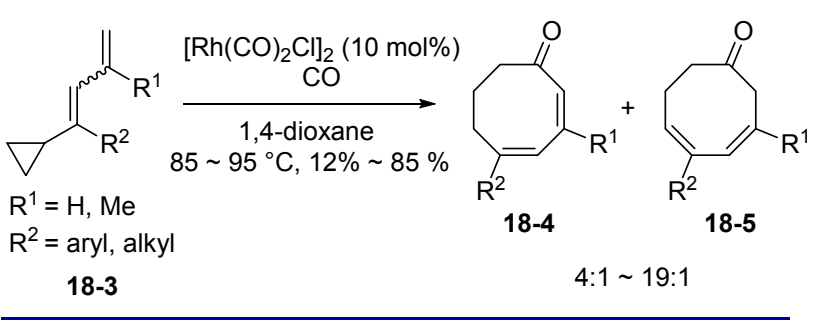

(C) Unexpected results of 1 -substituted BDCP

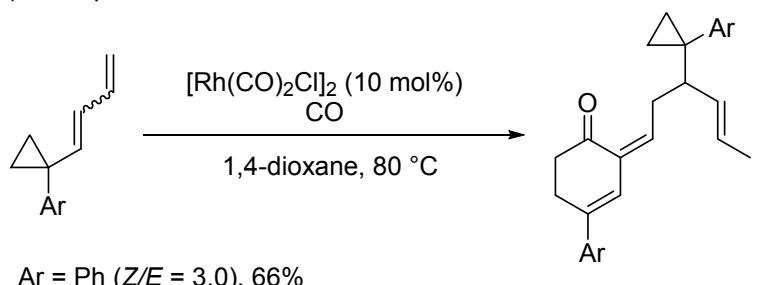

$\mathrm{Ar}=4-\mathrm{MeOC}_{6} \mathrm{H}_{4}(Z / E=5.4), 69 \%$

Scheme $18 \mathrm{Rh}(\mathrm{I})$-catalyzed [7+1] cycloaddition of BDCPs with $\mathrm{CO}$

In 2014, $\mathrm{Yu}$ and coworkers ${ }^{[72]}$ developed a rhodium-catalyzed benzo-[7+1] cycloaddition (Scheme 19). They proposed that cyclopropyl-benzocyclobutenes (CP-BCBs) 19-1 can be converted under high temperature to BDCP intermediates, which could then undergo $[7+1]$ cycloaddition, as the same as that shown in Scheme 18.
(A) Benzo-[7+1] cycloaddition to form benzo-eight-membered rings
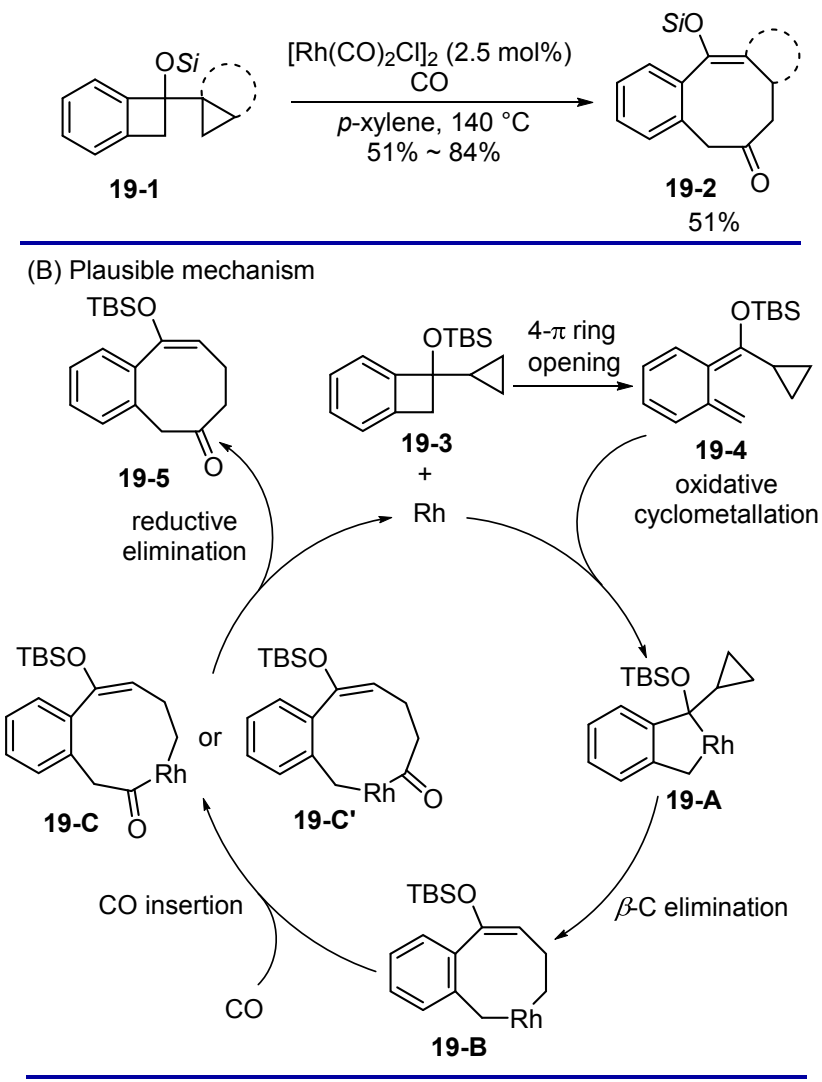

(C) Construction of 6-8-5 and 6-8-6 cycloadducts<smiles>COC1=C2CCCC2CC(=O)Cc2ccccc21</smiles><smiles>COC1=C2CCCCC2CC(=O)Cc2ccccc21</smiles>

Scheme 19 Rhodium-catalyzed benzo-[7+1] cycloaddition of $\mathrm{CP}-\mathrm{BCBs}$ with $\mathrm{CO}$

They proposed that the resulting BDCP 19-4, resulting from 19-3 by $4-\pi$ electrocyclic ring-opening, first undergoes rhodium-mediated cyclization to form rhodacyclopentane 19-A. Then, a benzorhodacyclooctene species 19-B is gen- 
erated through $a, \beta$-carbon elimination. The final cycloadduct 19-5 can then be generated through carbon monoxide insertion into the $\mathrm{C}-\mathrm{Rh}$ bond and reductive elimination. The reaction was efficient to generate aryl fused eight-membered ring compounds in high yields. Both 6/8/5 and 6/8/6 tricyclic molecules could also be obtained in moderate yields by this reaction.

\section{$7 \quad[5+2+1]$ cycloadditions}

Wender and coworkers ${ }^{[73]}$ reported the first threecomponent $[5+2+1]$ cycloaddition of VCPs, alkynes, and CO to form eight-membered carbocycle in 2002. In 2007, $\mathrm{Yu}$ and coworkers ${ }^{[70]}$ developed computationally and experimentally a two-component $[5+2+1]$ cycloaddition of ene-VCPs with $\mathrm{CO}$ by using rhodium catalyst, which can be applied to the construction of cis-5/8 bicycles, trans $-6 / 8$ bicycles, $5 / 8 / 5$ and $6 / 8 / 5$ tricycles (Scheme 20). This reaction has great potential in synthesizing various eight-membered carbocycles, considering that this reaction provides two common functional groups for further transformations, the alkene and carbonyl groups, in the final cycloadducts. This reaction has been applied in the synthesis of several natural products by $\mathrm{Yu}$ and coworkers, ${ }^{[7]}$ including asterisca-3(15),6-diene, ${ }^{[75]}$ pentalenene, ${ }^{[75]}$ hirsutene ${ }^{[76]}$ and 1-desoxylhypnophilin. ${ }^{[76]}$ Since 2010 , Yu and coworkers completed another two syntheses of natural products by using $[5+2+1]$ cycloaddition as the key reaction, which are illustrated in what follows.

Rhodium catalyzed [5+2+1] cycloaddition of ene-VCPs with $\mathrm{CO}$ and application to natural product synthesis
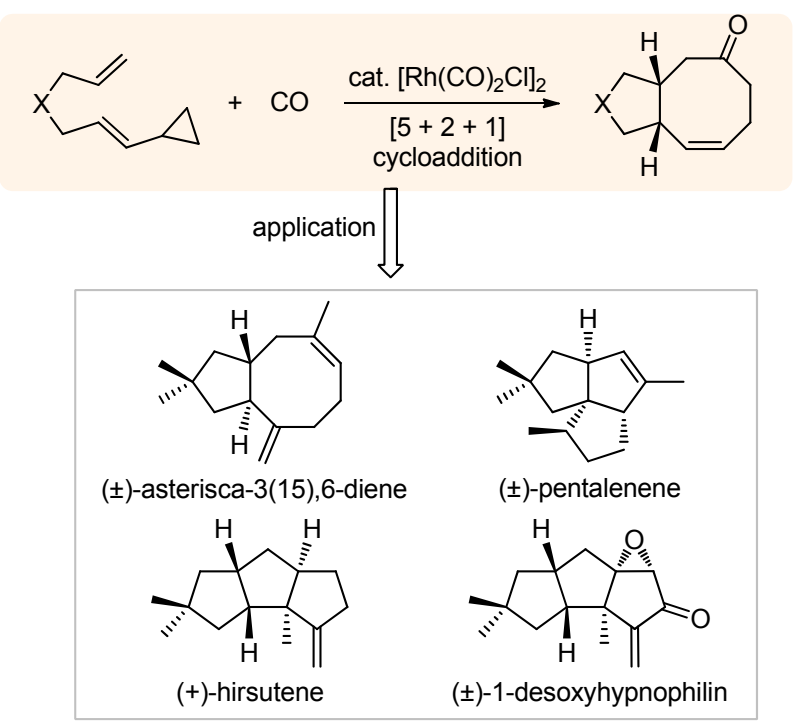

Scheme 20 Rhodium-catalyzed $[5+2+1]$ cycloaddition of ene-VCPs with $\mathrm{CO}$ and application to the synthesis of natural products

In 2010, Yu and coworkers reported a formal synthesis of hirsutic acid $\mathrm{C}$ (Scheme 21, A). ${ }^{[77]}$ An efficient tandem Rh-catalyzed $[5+2+1]$ cycloaddition/intramolecular aldol reaction successfully took place to generate the fused 5/5/5 cycloadduct 21-5 (and 21-6) possessing triquinane skeleton from a linear substrate. Compound 21-5 was converted to 21-7 through a Wittig reaction. Allylic oxidation of 21-7 using $\mathrm{SeO}_{2}$ and DMP, introduced a carbonyl group to the $5 / 5 / 5$ tricyclic intermediate. Then dehydrogenation of 21-8 to form 21-9 was realized by adding $\mathrm{TsOH}$, achieving the formal synthesis of hirsutic acid C, because compound 21-9 can be converted to the final natural product, as demonstrated by Schuda et al., Ikegami et al., and Banwell et al. ${ }^{[78]}$

In 2011, Yu and coworkers reported the asymmetric total synthesis of $(+)$-asteriscanolide using rhodium-catalyzed $[5+2+1]$ cycloaddition of ene-VCPs with $\mathrm{CO}$ as the key step (Scheme 21, B). ${ }^{[13]}$ Chiral substrate 21-13 could be synthesized in 3 steps from easily accessible starting compounds. Then cis-5/8 bicycle 21-14 was generated in 70\% yield by a $[5+2+1]$ cycloaddition. Compound 21-15 was synthesized from 21-14 in 4 steps, including enol trifluoromethanesulphonylation, coupling reaction, epoxidation, and ring opening of epoxide under basic conditions. Stereochemical inversion of hydroxyl group was achieved through an oxidation-reduction sequence. Then, compound 21-16 was treated with triphosgene and $\mathrm{PhSeH}$ to afford a selenocarbonate, which then via a radical cyclization gave the lactone 21-17. Unfortunately, this intermediate has an opposite carbon configuration compared with that in the target natural product. Due to this, the authors had to apply a reduction-dehydration-hydrogenation strategy to invert this wrong stereochemistry. Finally, $\mathrm{RuCl}_{3}-\mathrm{NaIO}_{4}$ oxidized the $\mathrm{C}-\mathrm{H}$ bond of one methylene moiety of 21-19 to a carbonyl group, completing the asymmetric total synthesis of $(+)$-asteriscanolide.

\section{Conclusions and perspectives}

Here we summarize the progresses in the last ten years about the development of new transition-metal-catalyzed cycloadditions for the synthesis of eight-membered carbocycles, together with the applications of the previously established metal-catalyzed cycloadditions in the synthesis of natural products. It is clearly evident from these progresses that more extensive research is required in this area.

Firstly, only a limited number of new cycloaddition reactions have been developed during this period for the synthesis of eight-membered carbocycles. In principle, various eight-membered carbocycle embedded molecules, which can be either already known molecules or the probable molecules to be discovered in the future, can be synthesized by using the reactions reported in this review and the previous review. But some molecules could have either skeletons, or substitutions, or stereochemistry that cannot be matched by the known cycloaddition reactions. Consequently, many tedious functional group transformations have to be performed and this leads to low efficiency of synthesis. In our opinions, developing more new cycloaddition reactions is critical to overcome these challenges so that synthesis of any molecules with eight-membered carbocycles, with consideration of atom and step-economy as 
(A) Formal total synthesis of Hirsutic acid C by $[5+2+1]$ cycloaddition/aldol reaction strategy

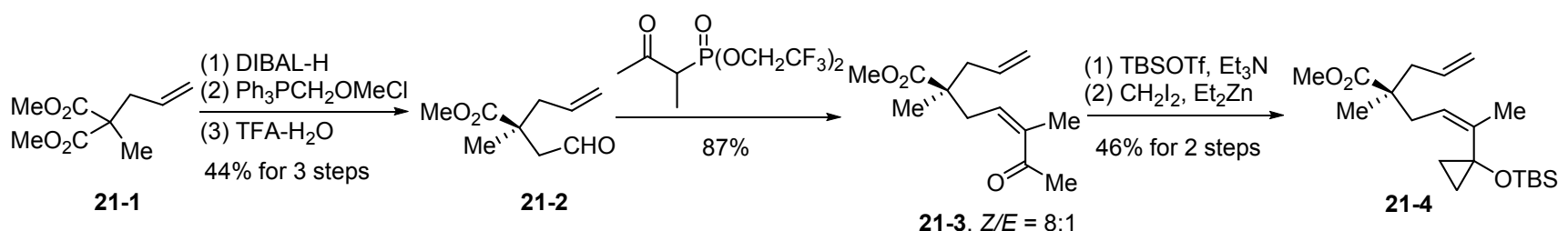

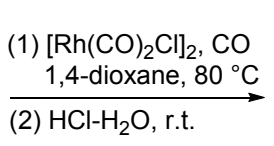

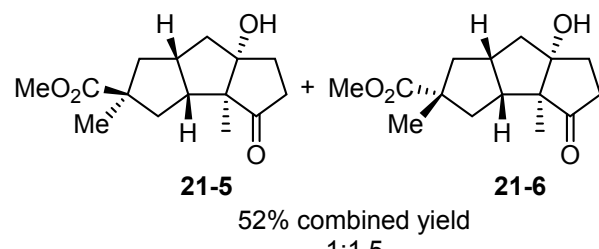<smiles>C=C1CC[C@]2(O)C[C@H]3C[C@](C)(C(=O)OCc4ccccc4)C[C@H]3[C@H]12</smiles>

21-7, 30\%, 75\% based on 21-5 and another diastereomers in $7 \%$ yield

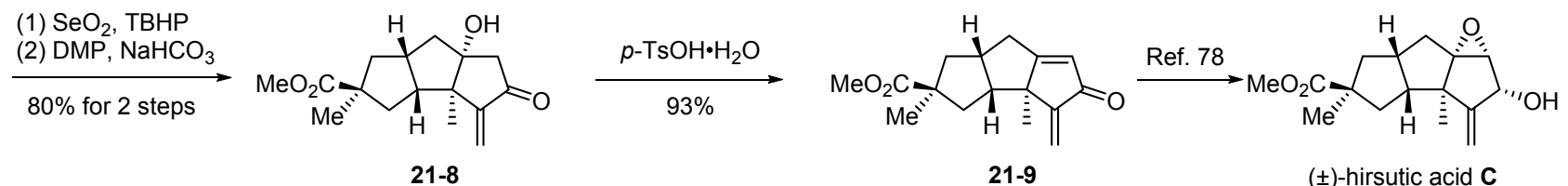

\section{(B) Total synthesis of $(+)$-Asteriscanolide by $[5+2+1]$ cycloaddition}

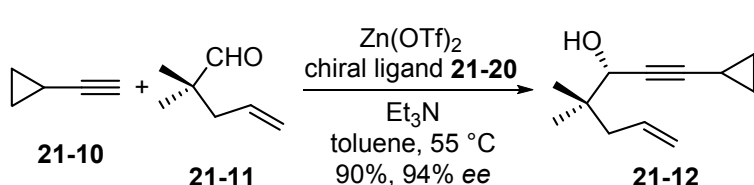

21-11

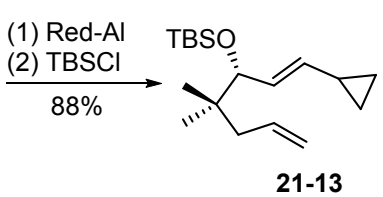

21-13

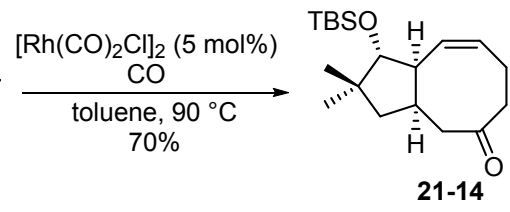

21-14
(1) $\mathrm{Tf}_{2} \mathrm{O}$
(2) $\mathrm{Fe}(\mathrm{acac})_{3}, \mathrm{MeMgBr}$ 1-methyl-2-pyrrolidinone
(3) $m$-CPBA
(4) TMP, $n$-BuLi, $\mathrm{Me}_{2} \mathrm{AlCl}$
$50 \%$ for 4 steps

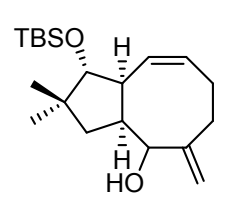

21-15

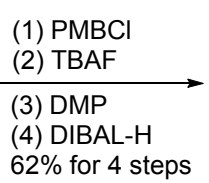

$62 \%$ for 4 steps

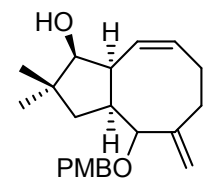

21-16

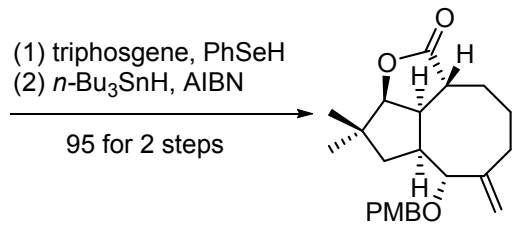

21-17

(2) $\mathrm{MsCl}$

(3) $\mathrm{Pd} / \mathrm{C}, \mathrm{H}_{2}$

(4) DMP

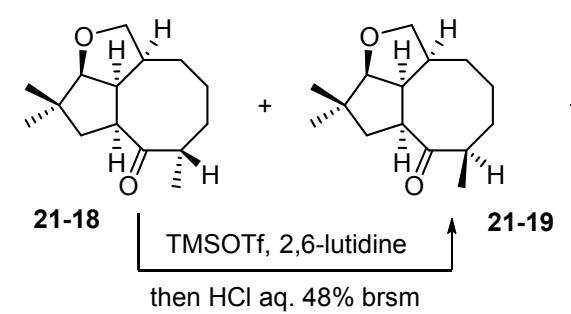

(+)-asteriscanolide

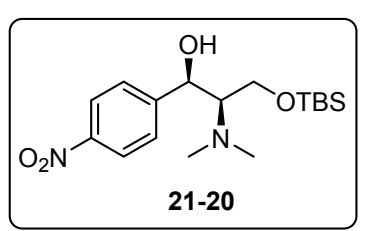

Scheme 21 Synthesis of natural products using [5+2+1] cycloaddition by Yu. (A) Formal synthesis of hirsutic acid C. (B) Total synthesis of $(+)$-asteriscanolide

well as green chemistry, can be realized.

Secondly, applications of the transition-metal-catalyzed cycloadditions in the total synthesis of natural products and pharmaceuticals are few so far. There are many challenges in the synthesis of complex natural products. But usually building the skeleton of the target molecule is the most difficult step. The transition-metal-catalyzed cycloadditions in many cases could provide the most straightforward ways to the target frameworks. This means that combining these reactions with others could provide new and creative strategies for shortening the synthesis. We encourage more leading chemists to use the transition-metal-catalyzed cy- 
cloadditions in synthesis of biologically active natural products.

Before concluding this review, we would like to mention our thoughts on further development of transition-metalcatalyzed cycloadditions for the eight-membered carbocycle synthesis, which could be helpful to chemists in the frontiers of reaction development. One is to design and try more combination of various carbon synthons, transition metals, and ligands. Figure 1 lists some of the carbon synthons in cycloadditions ${ }^{[79]}$. Furthermore, chemists need to develop more new carbon synthons to fill in Figure 1 so that many new combinations of carbon synthons, metals, ligands can be created and more possibilities to find new reactions can be realized. Certainly, serendipity is another opportunity to this aim, and we believe that many cycloaddition reactions will come out from hard-working and adventurous chemists in this field.

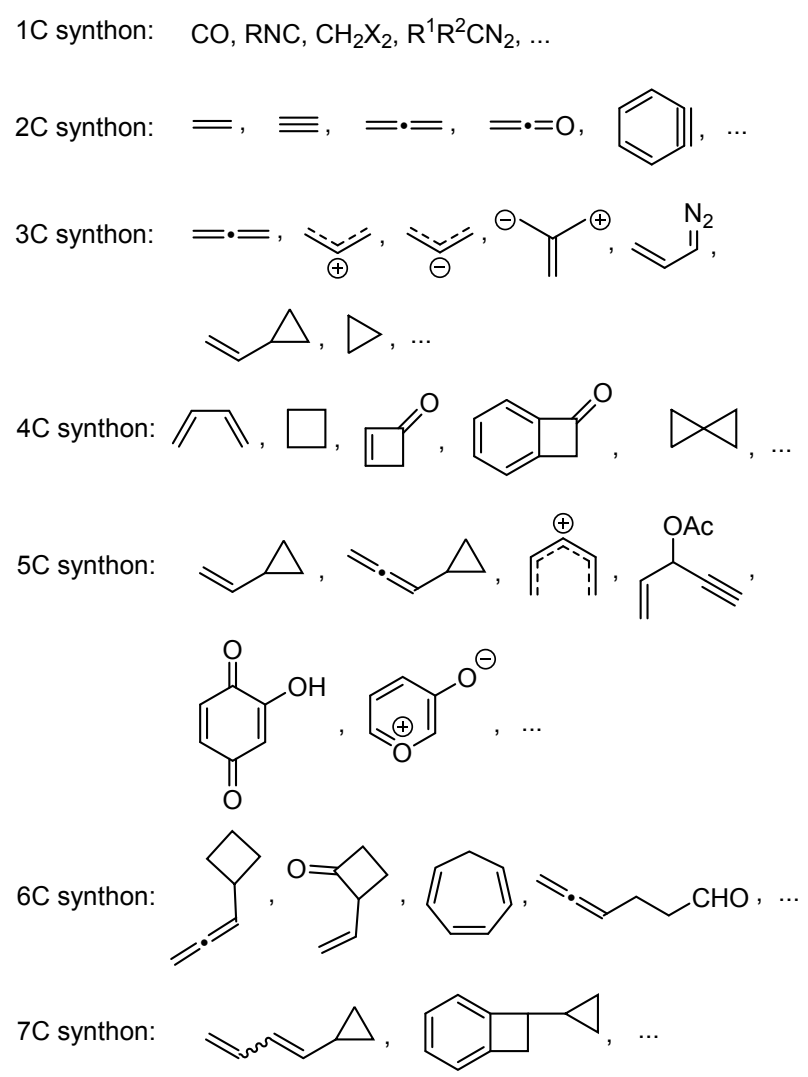

Figure 1 Selected carbon synthons in cycloadditions

\section{References}

[1] (a) Petasis, N. A.; Patane, M. A. Tetrahedron 1992, 48, 5757.

(b) Mehta, G.; Singh, V. Chem. Rev. 1999, 99, 881.

(c) Yet, L. Chem. Rev. 2000, 100, 2963.

[2] Suffness, M. Taxol: Science and Applications, CRC Press, Boca Raton, FL, 1995.

[3] (a) Tang, Y.-Z.; Liu, Y.-H.; Chen, J.-X. Mini-Rev. Med. Chem. 2012, 12,53 .

(b) Shang, R.; Wang, J.; Guo, W.; Liang, J. Curr. Top. Med. Chem. 2013, 13, 3013.

(c) Goethe, O.; Heuer, A.; Ma, X.; Wang, Z.; Herzon, S. B. Nat. Prod. Rep. 2019, 36, 220.

[4] (a) Armanino, N.; Charpentier, J.; Flachsmann, F.; Goeke, A.; Li- niger, M.; Kraft, P. Angew. Chem., Int. Ed. 2020, 59, 16310.

(b) Kraft, P.; Bajgrowicz, J. A.; Denis, C.; Fráter, G. Angew. Chem., Int. Ed. 2000, 39, 2980.

(c) Birkbeck, A. A. Challenges in the Synthesis of Natural and Non-Natural Volatiles. In The Chemistry and Biology of Volatiles, Ed.: Herrmann, A., John Wiley \& Sons, Ltd., New York, 2010, pp. $173 \sim 193$.

(d) Vesley, J. A.; Massie, S. N. US 3985769, 1976.

(e) Markert, T. WO 99/54430, 1998.

(f) Fráter, G.; Bajgrowicz, J. A.; Kraft, P. Tetrahedron 1998, 54, 7633.

(g) Granier, T.; Bajgrowicz, J. A.; Hanhart, A. US 7888309, 2011.

[5] (a) Martinez, H.; Ren, N.; Matta, M. E.; Hillmyer, M. A. Polym. Chem. 2014, 5, 3507.

(b) Hill, A. R.; Balogh, J.; Moncho, S.; Su, H.-L.; Tuba, R.; Brothers, E. N.; Al-Hashimi, M.; Bazzi, H. S. J. Polym. Sci., Part A: Polym. Chem. 2017, 55, 3137.

[6] For selected reviews for Diels-Alder reaction in synthesis, see: (a) Nicolaou, K. C.; Snyder, S. A.; Montagnon, T. Vassilikogiannakis. G. Angew. Chem., Int. Ed. 2002, 41, 1668.

(b) Takao, K.-I.; Munakata, R.; Tadano, K.-I. Chem. Rev. 2005, 105,4779

(c) Wessig, P.; Müller, G. Chem. Rev. 2008, 108, 2051.

(d) Funel, J.-A.; Abele, S. Angew. Chem., Int. Ed. 2013, 52, 3822.

(e) Jiang, X.; Wang, R. Chem. Rev. 2013, 113, 5515.

(f) Heravi, M. M.; Vavsari, V. F. RSC Adv. 2015, 5, 50890.

(g) Yang, B.; Gao, S. Chem. Soc. Rev. 2018, 47, 7926.

(h) Tasdelen, M. A. Polym. Chem. 2011, 2, 2133.

[7] Selected reviews for metal-catalyzed [4+2] reactions: (a) Reymond, S.; Cossy, J. Chem. Rev. 2008, 108, 5359.

(b) Carmona, D.; Lamata, M. P.; Oro, L. A. Coord. Chem. Rev. 2000, 200 202, 717 .

(c) Wender, P. A.; Smith, T. E. Tetrahedron 1998, 54, 1255.

(d) Frühauf, H.-W. Chem. Rev. 1997, 97, 523.

(e) Kagan, H. B.; Riant, O. Chem. Rev. 1992, 92, 1007.

(f) Robinson, J. E. Modern Rhodium-Catalyzed Organic Reactions; Ed.: Evans, P. A., Wiley-VCH Verlag GmbH \& Co. KGaA, Weinheim, Germany, 2005, pp. 241 262 .

[8] (a) Ben-Shoshan, R.; Sarel, S. J. Chem. Soc. D 1969, 883.

(b) Victor, R.; Ben-Shoshan, R.; Sarel, S. Tetrahedron Lett. 1970, 4253.

(c) Sarel, S. Acc. Chem. Res. 1978, 11, 204.

(d) Aumann, R. J. Am. Chem. Soc. 1974, 96, 2631.

(e) Taber, D. F.; Kanai, K.; Jiang, Q.; Bui, G. J. Am. Chem. Soc. 2000, 122,6807 .

(f) Taber, D. F.; Joshi, P. V.; Kanai, K. J. Org. Chem. 2004, 69, 2268.

(g) Kurahashi, T.; de Meijere, A. Synlett 2005, 2619.

(h) Iwasawa, N.; Owada, Y.; Matsuo, T. Chem. Lett. 1995, 115.

(i) Owada, Y.; Matsuo, T.; Iwasawa, N. Tetrahedron 1997, 53, 11069 .

(j) Murakami, M.; Itami, K.; Ubukata, M.; Tsuji, I.; Ito, Y. J. Org. Chem. 1998, 63, 4

(k) Shu, D.; Li, X.; Zhang, M.; Robichaux, P. J.; Tang, W. Angew. Chem., Int. Ed. 2011, 50, 1346.

(1) Grabowski, N. A.; Hughes, R. P.; Jaynes, B. S.; Rheingold, A. L. J. Chem. Soc., Chem. Commun. 1986, 1694.

(m) Cho, S. H.; Liebeskind, L. S. J. Org. Chem. 1987, 52, 2631.

(n) Semmelhack, M. F.; Ho, S.; Steigerwald, M.; Lee, M. C. J. Am. Chem. Soc. 1987, 109, 4397.

(o) Brancour, C.; Fukuyama, T.; Ohta, Y.; Ryu, I.; Dhimane, A.-L.; Fensterbank, L.; Malacria, M. Chem. Commun. 2010, 46, 5470.

(p) Jiang, G.-J.; Fu, X.-F.; Li, Q.; Yu, Z.-X. Org. Lett. 2012, 14, 692. (q) Li, X.; Song, W.; Tang, W. J. Am. Chem. Soc. 2013, 135, 16797. (r) Fukuyama, T.; Ohta, Y.; Brancour, C.; Miyagawa, K.; Ryu, I.; Dhimane, A.-L.; Fensterbank, L.; Malacria, M. Chem.-Eur. J. 2012, $18,7243$.

(s) Farley, C. M.; Sasakura, K.; Zhou, Y.-Y.; Kanale, V. V.; Uyeda, 
C. J. Am. Chem. Soc. 2020, 142, 4598.

[9] (a) Jiao, L.; Lin, M.; Zhuo, L.-G.; Yu, Z.-X. Org. Lett. 2010, 12, 2528 .

(b) Mazumder, S.; Shang, D.; Negru, D. E.; Baik, M.-H.; Evans, P. A. J. Am. Chem. Soc. 2012, 134, 20569.

(c) Kim, S.; Chung, Y. K. Org. Lett. 2014, 16, 4352.

(d) Wang, J.; Hong, B.; Hu, D.; Kadonaga, Y.; Tang, R.; Lei, X. J. Am. Chem. Soc. 2020, 142, 2238.

[10] Selected reviews for metal-catalyzed [2+2+2] reactions: (a) Vollhardt, K. P. C. Angew. Chem., Int. Ed. 1984, 23, 539.

(b) Chopade, P. R.; Louie, J. Adv. Synth. Catal. 2006, 348, 2307. (c) Kotha, S.; Brahmachary, E.; Lahiri, K. Eur. J. Org. Chem. 2005, 4741.

(d) Domínguez, G.; Pérez-Castells, J. Chem. Soc. Rev. 2011, 40, 3430 .

(e) Shibata, T.; Tsuchikama, K. Org. Biomol. Chem. 2008, 6, 1317. (f) Li, C.; Zhang, H.; Feng, J.; Zhang, Y.; Wang, J. Org. Lett. 2010, 12,3082.

(g) Shaw, M. H.; Melikhova, E. Y.; Kloer, D. P.; Whittingham, W. G.; Bower, J. F. J. Am. Chem. Soc. 2013, 135, 4992.

[11] (a) Deiters, A.; Martin, S. F. Chem. Rev. 2004, 104, 2199.

(b) Grubbs, R. H.; Miller, S. J.; Fu, G. C. Acc. Chem. Res. 1995, 28, 446.

(c) Fürstner, A. Top. Catal. 1997, 4, 285

(d) Donohoe, T. J.; Orr, A. J.; Bingham, M. Angew. Chem., Int. Ed. 2006, 45,2664

(e) Maier, M. E. Angew. Chem., Int. Ed. 2000, 39, 2073.

(f) Michaut, A.; Rodriguez, J. Angew. Chem., Int. Ed. 2006, 45, 5740 .

[12] Hu, Y.-J.; Li, L.-X.; Han, J.-C.; Min, L.; Li, C.-C. Chem. Rev. 2020, $120,5910$.

[13] (a) Liang, Y.; Jiang, X.; Yu, Z.-X. Chem. Commun. 2011, 47, 6659. (b) Liang, Y.; Jiang, X.; Fu, X.-F.; Ye, S.; Wang, T.; Yuan, J.; Wang, Y.; Yu, Z.-X. Chem.-Asian J. 2012, 7, 593.

[14] (a) Illuminati, G.; Mandolini, L. Acc. Chem. Res. 1981, 14, 95. (b) Galli, C.; Mandolini, L. Eur. J. Org. Chem. 2000, 2000, 3117.

[15] Lautens, M.; Klute, W.; Tam, W. Chem. Rev. 1996, 96, 49.

[16] Yu, Z.-X.; Wang, Y.; Wang, Y. Chem.-Asian J. 2010, 5, 1072.

[17] (a) Reed, H. W. B. J. Chem. Soc. 1954, 1931.

(b) Ziegler, K.; Holzkamp, E.; Breil, H.; Martin, H. Angew. Chem. 1955, 67, 426

[18] Wender, P. A.; Ihle, N. C. J. Am. Chem. Soc. 1986, 108, 4678.

[19] Park, J. W.; Park, J. E.; Park, J. H.; Hong, M. R.; Kim, S. M.; Chung, Y. K.; Kim, C. H. Synlett 2016, 27, 455.

[20] Llorente, N.; Fernández-Pérez, H.; Bauzá, A.; Frontera, A.; Vidal-Ferran, A. Catal. Sci. Technol. 2018, 8, 5251.

[21] (a) tom Dieck, H.; Dietrich, J. Chem. Ber. 1984, 117, 694. (b) tom Dieck, H.; Dietrich, J. Angew.Chem., Int. Ed. 1985, 24, 781. (c) Mallien, M.; Haupt, E. T. K.; tom Dieck, H. Angew. Chem., Int. Ed. 1988, 27, 1062.

[22] Lee, H.; Campbell, M. G.; Sánchez, R. H.; Börgel, J.; Raynaud, J.; Parker, S. E.; Ritter, T. Organometallics 2016, 35, 2923.

[23] Kennedy, C. R.; Zhong, H. Y.; Macaulay, R. L.; Chirik, P. J. J. Am. Chem. Soc. 2019, 141, 8557.

[24] (a) Braconi, E.; Götzinger, A. C.; Cramer, N. J. Am. Chem. Soc. 2020, DOI: $10.1021 /$ jacs.0c09486.

(b) Baldenius, K.-U.; tom Dieck, H.; König, W. A.; Icheln, D.; Runge, T. Angew. Chem., Int. Ed. 1992, 31, 305.

[25] Selected reviews for metal-catalyzed $\mathrm{C}-\mathrm{C}$ bond activation of strained rings: (a) Murakami, M.; Matsuda, T. Chem. Commun. 2011, 47, 1100 .

(b) Ruhland, K. Eur. J. Org. Chem. 2012, 2012, 2683.

(c) Souillart, L.; Cramer, N. Chem. Rev. 2015, 115, 9410

(d) Chen, F.; Wang, T.; Jiao, N. Chem. Rev. 2014, 114, 8613.

(e) Cleavage of Carbon-Carbon Single Bonds by Transition Metals, Eds.: Murakami, M.; Chatani, N., Wiley-VCH, Weinheim, Germany, 2016.

(f) Dong, G. C-C Bond Activation, in Topics in Current Chemis- try, Eds.: Bayley, H.; Houk, K. N.; Hughes, G.; Hunter, C. A.; Ishihara, K.; Krische, M. J.; Lehn, J.-M.; Luque, R.; Olivucci, M.; Siegel, J. S.; Thiem, J.; Venturi, M.; Wong, C.-H.; Wong, H. N. C; You, S.-L.; Yam, V. W.-W.; Yan, C. Springer Verlag, Berlin and Heidelberg, Germany, 2014, DOI: 10.1007/978-3-642-55055-3.

(g) Rubin, M.; Rubina, M.; Gevorgyan, V. Chem. Rev. 2007, 107, 3117.

(h) Fumagalli, G.; Stanton, S.; Bower, J. F. Chem. Rev. 2017, 117, 9404.

(i) Dai, H.; Wu, F.; Bai, D. Chin. J. Org. Chem. 2020, 40, 1423 (in Chinese).

(代洪雪，吴芬，白大昌，有机化学， 2020, 40, 1423 .

[26] (a) Evans, J. A.; Everitt, G. F.; Kemmitt, R. D. W.; Russell, D. R. J. Chem. Soc., Chem. Commun. 1973, 158.

(b) Liebeskind, L. S.; Baysdon, S. L.; South, M. S.; Blount, J. F. J. Organomet. Chem. 1980, 202, C73.

(c) Liebeskind, L. S.; Baysdon, S. L.; South, M. S.; Iyer, S.; Leeds, J. P. Tetrahedron 1985, 41, 5839.

(d) Huffman, M. A.; Liebeskind, L. S.; Pennington, W. T. Organometallics 1990, 9, 2194.

(e) Masuda, Y.; Hasegawa, M.; Yamashita, M.; Nozaki, K.; Ishida, N.; Murakami, M. J. Am. Chem. Soc. 2013, 135, 7142.

(f) Okumura, S.; Sun, F.; Ishida, N.; Murakami, M. J. Am. Chem. Soc. 2017, 139, 12414.

(g) Xu, T.; Dong, G. Angew. Chem., Int. Ed. 2012, 51, 7567.

(h) Xu, T.; Ko, H. M.; Savage, N. A.; Dong, G. J. Am. Chem. Soc. 2012, 134, 20005.

(i) Deng, L.; Chen, M.; Dong, G. J. Am. Chem. Soc. 2018, 140 , 9652.

(j) Lu, G.; Fang, C.; Xu, T.; Dong, G.; Liu, P. J. Am. Chem. Soc. 2015, 137, 8274

(k) Xu, T.; Savage, N. A.; Dong, G. Angew. Chem., Int. Ed. 2014, 53, 1891.

(1) Chen, P.-H.; Xu, T.; Dong, G. Angew. Chem., Int. Ed. 2014, 53, 1674.

(m) Sun, T. W.; Zhang, Y.; Qiu, B.; Wang, Y.; Qin, Y.; Dong, G.; Xu, T. Angew. Chem., Int. Ed. 2018, 57, 2859.

(n) Deng, L.; Xu, T.; Li, H.; Dong, G. J. Am. Chem. Soc. 2016, 138, 369.

(o) Chen, P.-H.; Sieber, J.; Senanayake, C. H.; Dong, G. Chem. Sci. 2015, 6, 5440 .

(p) Zhu, Z.; Li, X.; Chen, S.; Chen, P.-H.; Billett, B. A.; Huang, Z.; Dong, G. ACS Catal. 2018, 8,845 .

(q) Xu, Z.-Y.; Zhang, S.-Q.; Liu, J.-R.; Chen, P.-P.; Li, X.; Yu, H.-Z.; Hong, X.; Fu, Y. Organometallics 2018, 37, 592.

(r) Bender, M.; Turnbull, B. W. H.; Ambler, B. R.; Krische, M. J. Science 2017, 357, 779.

(s) Ambler, B. R.; Turnbull, B. W. H.; Suravarapu, S. R.; Uteuliyev, M. M.; Huynh, N. O.; Krische, M. J. J. Am. Chem. Soc. 2018, 140, 9091.

(t) Deng, L.; Dong, G. Trends in Chem. 2020, 2, 183.

[27] Juliá-Hernández, F.; Ziadi, A.; Nishimura, A.; Martin, R. Angew. Chem., Int. Ed. 2015, 54, 9537.

[28] Yang, S.; Xu, Y.; Li, J. Org. Lett. 2016, 18, 6244.

[29] Zou, H.; Wang, Z.-L.; Huang G. Chem.-Eur J. 2017, 23, 12593.

[30] Reppe, W.; Schlichting, O.; Klager, K.; Toepel, T. Liebigs Ann. Chem. 1948, 560, 1.

[31] (a) Wender, P. A.; Christy, J. P. J. Am. Chem. Soc. 2007, 129, 13402. (b) Wender, P. A.; Christy, J. P.; Lesser, A. B.; Gieseler, M. T. Angew. Chem., Int. Ed. 2009, 48, 7687.

[32] Chai, Z.; Wang, H.-F.; Zhao, G. Synlett 2009, 11, 1785.

[33] Nasrallah, D. J.; Croatt, M. P. Eur. J. Org. Chem. 2014, 2014, 3767.

[34] Greco, A.; Carbonar, A.; Dall'Asta, G. J. Org. Chem. 1970, 35, 271.

[35] Murakami, M.; Ashida, S.; Matsuda, T. J. Am. Chem. Soc. 2006, 128, 2166.

[36] Tao, J.-Y.; Fang, D.-C.; Chass, G. A. Phys. Chem. Chem. Phys. 2012, 14, 6937.

[37] Lainhart, B. C.; Alexanian, E. J. Org. Lett. 2015, 17, 1284. 
[38] Gilbertson, S. R.; DeBoef, B. J. Am. Chem. Soc. 2002, 124, 8784

[39] DeBoef, B.; Counts, W. R.; Gilbertson, S. R. J. Org. Chem. 2007, $72,799$.

[40] Canlas, G. M. R.; Gilbertson, S. R. Chem. Commun. 2014, 50, 5007.

[41] (a) Evans, P. A.; Robinson, J. E.; Baum, E. W.; Fazal, A. N. J. Am. Chem. Soc. 2002, 124, 8782 .

(b) Evans, P. A.; Baum, E. W. J. Am. Chem. Soc. 2004, 126, 11150.

(c) Evans, P. A.; Baum, E. W.; Fazal, A. N.; Pink, M. Chem. Commun. 2005, 63 .

[42] Wender, P. A.; Christy, J. P. J. Am. Chem. Soc. 2006, 128, 5354.

[43] (a) Hilt, G.; Janikowski, J. Angew. Chem., Int. Ed. 2008, 47, 5243. (b) Varela, J. A.; Castedo, L.; Saá, C. Org. Lett. 2003, 5, 2841.

[44] Yamasaki, R.; Ohashi, M.; Maeda, K.; Kitamura, T.; Nakagawa, M.; Kato, K.; Fujita, T.; Kamura, R.; Kinoshita, K.; Masu, H.; Azumaya, I.; Ogoshi, S.; Saito, S. Chem.-Eur J. 2013, 19, 3415.

[45] Jiménez, T.; Carreras, J.; Ceccon, J.; Echavarren, A. M. Org. Lett. 2016, 18,1410 .

[46] Davis, R. E.; Dodds, T. A.; Hseu, T. H.; Wagnon, J. C.; Devon, T.; Tancrede, J.; McKennis, J. S.; Pettit, R. J. Am. Chem. Soc. 1974, 96, 7562.

[47] D'yakonov, V. A.; Kadikova, G. N.; Dzhemilev, U. M. Russ. Chem. Rev. 2018, 87, 797.

[48] (a) Mach, K.; Antropiusová, H.; Sedmera, P.; Hanuš, V.; Tureček, F. J. Chem. Soc., Chem. Commun. 1983, 805.

(b) Mach, K.; Antropiusová, H.; Petrusová, L.; Hanuš, V.; Tureček, F.; Sedmera, P. Tetrahedron 1984, 40, 3295.

[49] D'yakonov, V. A.; Kadikova, G. N.; Dzhemilev, U. M. Tetrahedron Lett. 2011, 52, 2780.

[50] D'yakonov, V. A.; Kadikova, G. N.; Khalilov, L. M.; Dzhemilev, U. M. Russ. J. Org. Chem. 2013, 49, 1139.

[51] Dzhemilev, U. M.; Kadikova, G. N.; Kolokol'tsev, D. I.; D'yakonov, V. A. Tetrahedron 2013, 69, 4609.

[52] (a) D'yakonov, V. A.; Kadikova, G. N.; Kolokol'tsev, D. I.; Ramazanov, I. R.; Dzhemilev, U. M. J. Organomet. Chem. 2015, 794, 23. (b) D'yakonov, V. A.; Kadikova, G. N.; Kolokol'tsev, D. I.; Ramazanov, I. R.; Dzhemilev, U. M. Eur. J. Org. Chem. 2015, $2015,4464$.

(c) D'yakonov, V. A.; Kadikova, G. N.; Nasretdinov, R. N.; Kolokol'tsev, D. I.; Dzhemilev, U. M. Tetrahedron Lett. 2017, 58, 1714 .

(d) D'yakonov, V. A.; Kadikova, G. N.; Khalilov, L. M.; Dzhemilev, U. M. Russ. J. Org. Chem. 2018, 54, 832.

[53] Achard, M.; Tenaglia, A.; Buono, G. Org. Lett. 2005, 7, 2353.

[54] Achard, M.; Mosrin, M.; Tenaglia, A.; Buono, G. J. Org. Chem. 2006, 71, 2907

[55] Clavier, H.; Le Jeune, K.; de Riggi, I.; Tenaglia, A.; Buono, G. Org. Lett. 2011, 13, 308.

[56] (a) D'yakonov, V. A.; Kadikova, G. N.; Gazizullina, G. F.; Khalilov, L. M.; Dzhemilev, U. M. Tetrahedron Lett. 2015, 56, 2005.

(b) D'yakonov, V. A.; Kadikova, G. N.; Gazizullina, G. F.; Dzhemilev, U. M. Russ. Chem. Bull. 2016, 65, 200.

[57] D'yakonov, V. A.; Kadikova, G. N.; Gazizullina, G. F.; Dzhemilev, U. M. ChemistrySelect 2018, 3, 6221.

[58] (a) D'yakonov, V. A.; Kadikova, G. N.; Nasretdinov,R. N.; Dzhemileva, L. U.; Dzhemilev, U. M. Eur. J. Org. Chem. 2020, 623.

(b) Kadikova, G. N.; D'yakonov, V. A.; Nasretdinov, R. N.; Dzhemileva, L. U.; Dzhemilev, U. M. Mendeleev Commun. 2020, 30,318 .

[59] Oonishi, Y.; Hosotani, A.; Sato, Y. J. Am. Chem. Soc. 2011, 133, 10386.

[60] Oonishi, Y.; Hosotani, A.; Sato, Y. Angew. Chem., Int. Ed. 2012, 51, 11548.
[61] Liu, T.; Han, L.; Han, S.; Bi, S. Organometallics 2015, 34, 280.

[62] (a) Xia, Y.; Liang, Y.; Chen, Y.; Wang, M.; Jiao, L.; Huang, F.; Liu, S.; Li, Y.; Yu, Z.-X. J. Am. Chem. Soc. 2007, 129, 3470.

(b) Shi, F.-Q.; Li, X.; Xia, Y.; Zhang, L.; Yu, Z.-X. J. Am. Chem. Soc. 2007, 129, 15503.

(c) Liang, Y.; Liu, S.; Xia, Y.; Li, Y.; Yu, Z.-X. Chem.-Eur J. 2008, 14, 4361.

(d) Liang, Y.; Zhou, H.; Yu, Z.-X. J. Am. Chem. Soc. 2009, 131, 17783

(e) Liang, Y.; Liu, S.; Yu, Z.-X. Synlett 2009, 905

(f) Mercier, E.; Fonovic, B.; Henry, C.; Kwon, O.; Dudding, T. Tetrahedron Lett. 2007, 48, 3617.

(g) González, I.; Pla-Quintana, A.; Roglans, A.; Dachs, A.; Solà, M.; Parella, T.; Farjas, J.; Roura, P.; Lloveras, V.; Vidal-Gancedo, J. Chem. Commun. 2010, 46, 2944.

(h) Zhao, L.; Wen, M.; Wang, Z.-X. Eur. J. Org. Chem. 2012, 19, 3587.

[63] Faustino, H.; Alonso, I.; Mascareñas, J. L.; López, F. Angew. Chem., Int. Ed. 2013, 52, 6526.

[64] Faustino, H.; Bernal, P.; Castedo, L.; López, F.; Mascareñas, J. L. Adv. Synth. Catal. 2012, 354, 1658.

[65] (a) Rigby, J. H.; Henshilwood, J. A. J. Am. Chem. Soc. 1991, 113, 5122 .

(b) Rigby, J. H.; Ateeq, H. S.; Charles, N. R.; Henshilwood, J. A.; Short, K. M.; Sugathapala, P. M. Tetrahedron 1993, 49, 5495.

(c) Rigby, J. H.; Ahmed, G.; Ferguson, M. D. Tetrahedron Lett. 1993, 34, 5397.

(d) Rigby, J. H.; Sandanayaka, V. P. Tetrahedron Lett. 1993, 34, 935.

(e) Rigby, J. H.; Pigge, F. C.; Ferguson, M. D. Tetrahedron Lett. 1994, 35, 8131.

(f) Rigby, J. H.; Sugathapala, P.; Heeg, M. J. J. Am. Chem. Soc. 1995, 117,8851 .

(g) Rigby, J. H.; Kondratenko, M. A.; Fiedler, C. Org. Lett. 2000, 2, 3917.

(h) Rigby, J. H.; Laurent, S. B.; Kamal, Z.; Heeg, M. J. Org. Lett. 2008, $10,5609$.

[66] Rigby, J. H.; Kirova-Snover, M. Tetrahedron Lett. 1997, 38, 8153.

[67] De, S.; Misra, S.; Rigby, J. H. Org. Lett. 2015, 17, 3230.

[68] Magauer, T.; Mulzer, J.; Tiefenbacher, K. Org. Lett. 2009, 11, 5306.

[69] Yao, Z.-K.; Li, J.; Yu, Z.-X. Org. Lett. 2011, 13, 134.

[70] Wang, Y.; Wang, J.; Su, J.; Huang, F.; Jiao, L.; Liang, Y.; Yang, D.; Zhang, S.; Wender, P. A.; Yu, Z.-X. J. Am. Chem. Soc. 2007, 129, 10060 .

[71] Jiang, G.-J.; Fu, X.-F.; Li, Q.; Yu, Z.-X. Org. Lett. 2012, 14, 692

[72] Fu, X.-F.; Xiang, Y.; Yu, Z.-X. Chem.-Eur J. 2015, 21, 4242.

[73] Wender, P. A.; Gamber, G. G.; Hubbard, R. D.; Zhang, L. J. Am. Chem. Soc. 2002, 124, 2876.

[74] Wang, Y.; Yu, Z.-X. Acc. Chem. Res. 2015, 48, 2288.

[75] Fan, X.; Zhuo, L.-G.; Tu, Y. Q.; Yu, Z.-X. Tetrahedron 2009, 65, 4709.

[76] Jiao, L.; Yuan, C.; Yu, Z.-X. J. Am. Chem. Soc. 2008, 130, 4421.

[77] Yuan, C.; Jiao, L.; Yu, Z.-X. Tetrahedron Lett. 2010, 51, 5674.

[78] (a) Schuda, P. F.; Phillips, J. L.; Morgan, T. M. J. Org. Chem. 1986, $51,2742$.

(b) Nishida, M.; Iseki, K.; Shibasaki, M.; Ikegami, S. Chem. Pharm. Bull. 1990, 38, 3230.

(c) Banwell, M. G.; Austin, K. A. B.; Willis, A. C. Tetrahedron 2007, 63, 6388 .

[79] Fan, X.; Liu, C.-H.; Yu, Z.-X. Rhodium(I)-Catalyzed Cycloadditions Involving Vinylcyclopropanes and Their Derivatives. In Rhodium Catalysis in Organic Synthesis, Ed.: Tanaka, K., Wiley-VCH, Weinheim, Germany, 2019, pp. 229 276.

(Sun, H.) 